\title{
A climate-change attribution retrospective of some impactful weather extremes of 2021
}

\author{
Davide Faranda ${ }^{1,2,3}$, Stella Bourdin ${ }^{1}$, Mireia Ginesta ${ }^{1}$, Meriem Krouma ${ }^{1}$, Gabriele Messori ${ }^{4,5}$, \\ Robin Noyelle ${ }^{1}$, Flavio Pons ${ }^{1}$, and Pascal Yiou ${ }^{1}$ \\ ${ }^{1}$ Laboratoire des Sciences du Climat et de l'Environnement, UMR 8212 CEA-CNRS-UVSQ, Université Paris-Saclay, IPSL, \\ 91191 Gif-sur-Yvette, France \\ ${ }^{2}$ London Mathematical Laboratory, 8 Margravine Gardens London, W6 8RH, UK \\ ${ }^{3}$ LMD/IPSL, Ecole Normale Superieure, PSL research University, Paris, France \\ ${ }^{4}$ Department of Earth Sciences and Centre of Natural Hazards and Disaster Science (CNDS), Uppsala University, Uppsala, \\ Sweden \\ ${ }^{5}$ Department of Meteorology and Bolin Centre for Climate Research, Stockholm University, Stockholm, Sweden
}

Correspondence: Davide Faranda (davide.faranda@cea.fr)

\begin{abstract}
The IPCC report AR6 indicates a general consensus that anthropogenic climate change is modifying frequency and intensity of class of extreme events such as cold spells, heatwaves, storms or floods. A different point of view is to investigate whether a specific extreme event would have been possible in the absence of climate change, or whether climate change may have affected its specific characteristics. Here, we address this question by performing an attribution of some major extreme events that occurred in 2021 over Europe and North America: the winter storm Filomena, the French Spring cold spell, the Westphalia Floods, the Mediterranean summer heatwave, the hurricane Ida, the Po Valley tornadoes outbreak, the medicane Apollo and the late autumn Scandinavian cold-spell. We focus on the role of the atmospheric circulation associated with the events and its likelihood in present (factual world) and past climate conditions (counterfactual world) - defined using the ERA5 dataset 1950 to present. We use an analogs-based methodology whose aim is to find the most similar sea-level pressure patterns to the target events in the factual and counterfactual worlds and compute significant shifts in probability, persistence, predictability and seasonality of the patterns. We also diagnose whether in the present climate the analogs of the studied events lead to warmer/cooler or dryer/wetter conditions than in the past. We find that most of the events are significantly modified in present climate with respect to the past, because of changes in position, persistence and seasonality of cyclonic/anticyclonic patterns. Two of the events, storm Filomena and Medicane Apollo, appears to be a black swan of the atmospheric circulation, with analogs of bad quality. Our approach, complementary to the statistical methods already available in the community, warns that the role of the atmospheric circulation should be taken into account when performing attribution studies.
\end{abstract}




\section{Introduction}

One of the main novelties of the latest IPCC AR6 report (Allan et al., 2021) with respect to previous IPCC documents is the increased confidence that anthropogenic climate change is critically affecting the dynamics of weather extremes. For summer, the AR6 report states that we are already observing prolonged periods of extremely warm conditions (Horton et al., 2016) with increased droughts leading to forest fires (Flannigan et al., 2000), species extinctions (Román-Palacios and Wiens, 2020) and health issues for vulnerable populations (Mitchell et al., 2016). In winter, increased persistence of cyclonic and anticyclonic structures leads to extremely wet and dry periods (Ogawa et al., 2018), the latter associated with foggy weather and smog accumulation in urban areas (Sachweh and Koepke, 1995; Hu et al., 2020). Finally, the IPCC also warns that, in the shoulder seasons, we observe a large variability of rains associated with both tropical and extratropical storms and convective events, leading to an alteration of the hydrological cycle (Gordon et al., 2005; Bala et al., 2010; Pendergrass et al., 2017). These trends are expected to accelerate in the coming years, if the global efforts to reduce carbon emissions are not implemented swiftly (Trisos et al., 2020).

While these assessments are meaningful when considering (relatively) large ensembles of extreme events with similar characteristics, it is also important to evaluate whether the probability of occurrence, or physical characteristics, of a single extreme event have been influenced by anthropogenic climate change. This knowledge builds awareness of the consequences of greenhouse gas emissions in the general public, and allows stakeholders to evaluate specific impacts induced by climate change. For these reasons, attributing a single extreme event to climate change has given rise to a wealth of studies, an entire field named attribution (Shepherd, 2016; Jézéquel et al., 2018; Naveau et al., 2020; van Oldenborgh et al., 2021).

Studies in extreme events attribution are conventionally grounded in extreme value theory (Trenberth et al., 2015), which they use to estimate return times of threshold exceedances of particulars observables (e.g. temperatures above or below a target value for a certain number of consecutive days for heatwaves and cold-spells). The main drawback of such statistical attribution is that it does not take into account the physical processes leading to the extreme events. Climate change is likely associated with dynamical changes in the atmosphere (e.g. Stendel et al., 2021), yet the conventional extreme value approach overlooks these entirely. This brought Shepherd (2014) to argue that the atmospheric circulation is a key element of the uncertainty in attribution studies, and in parallel stimulated attempts to incorporate knowledge of the atmospheric circulation into an attribution framework (Shepherd, 2016; Yiou et al., 2017).

Here, we build upon this line of work by performing an attribution of some notable extremes occurring during the 2021 calendar year based on large-scale atmospheric drivers. In particular, we analyze: i) the winter storm Filomena which caused, in January, heavy snowfalls and extremely cold conditions in Spain; ii) the late cold spell that occurred in April 2021 in France with large impacts on vegetation and agriculture; iii) the July floods in Westphalia, Germany, responsible for the destruction of entire villages, infrastructure and heavy loss of lives; iv) the record-breaking temperatures during the August Mediterranean heatwave and the associated wildfires in Greece and Italy; v) the September Po Valley tornado outbreak; vi) Hurricane Ida, which caused heavy damage in Louisiana and New York city; vii) the medicane (Mediterranean Hurricane) Apollo which occurred in Sicily in October; and viii) the November Scandinavian cold spell. 
In order to attribute these events to climate change, we study the concurrent atmospheric circulation patterns and we search for pattern recurrences in the far (1950-1979) and recent past (1992-2021). Our working hypothesis is that the far past acts as a counterfactual world where the Earth's climate was less heavily influenced by anthropogenic forcing when compared to the recent past (the factual world). Additionally, we assume that 30 years is a long enough period to average out the interannual variability of the atmospheric motions (as that caused, for example, by the El Nino-Southern Oscillation) and the climate within these periods can be assumed (quasi)stationary with respect to the climate change signal. We present in Section 2 the methodological aspects of this work, introducing in Section 3 the relevant assessment metrics. The Section 4 contains, for each event: i) a description, ii) a state-of-the art of climate-change aspects related to the event and iii) our attribution analyses. Our conclusions are presented in Section 5.

\section{A method for attribution of extreme events to climate change which takes into account changes in atmospheric circulation}

We study changes in weather patterns associated with extreme events by leveraging the framework of weather analogs (Yiou et al., 2003). We first identify the peak day of each extreme event. We then perform a semi-objective detection of the concurrent large-scale weather pattern using daily average sea-level pressure $(s l p)$ from the ERA5 reanalysis databas eover 1950-2021. The semi-objectivity lies in the exact choice of geographical domain over which the pattern is identified. For cyclones, the domain of the analysis can be easily identified as the low-pressure area associated with the storm. For cold spells and heatwaves, we follow Stefanon et al. (2012), who have shown that these events have a large scale dynamical footprint spanning the size of the European continent. For all cases, we have tested that our method is qualitatively insensitive to modest changes in the domain size. Four our analysis, we split the ERA5 dataset into two periods: 1950-1979 and 1992-2021. We take the first period to represent a counterfactual world with a weaker anthropogenic influence on climate than in the second period, which represents our factual world affected by anthropogenic climate change. For each period, we scan scan all the daily average $s l p$ maps and select the best 33 analogs, namely the maps minimizing the euclidean distance with respect to the map of the event itself. The number of 33 corresponds approximately to the smallest 3\%o of euclidean distances in each subset of our data. We have tested extracting between 25 and 50 analogue maps, without finding any qualitatively large differences in our results. Note that for the factual period, as common practise in attribution studies, the event itself is removed. Furthermore, we forbid the analogs search in a window of a week centered around the date of the event. We do not restrict the analogs search to a specific season, which allows us to identify possible seasonality shifts between the counterfactual and factual periods. We then compute the average map for all analogs in each of the two periods, and take the difference between the two averages $(\Delta s l p)$. To determine significant changes between the two periods, we adopt a bootstrap procedure which consists of pooling the dates from the two periods together, randomly extracting 33 dates from this pool 1000 times, creating the corresponding difference maps and marking as significant only grid point changes above two standard deviations of the bootstrap sample. We also plot the 2-meter temperature $(t 2 m)$ and daily precipitation rate fields $(t p)$ on the dates of the closest $s l p$ analogs, repeating the same bootstrap procedure to identify significant changes. 


\section{Evaluation Metrics}

Following Faranda et al. (2020), we define some quantities that support our interpretation of the analogs-based attribution. All of these may then be compared between the counterfactual and factual periods.

- Analogue Quality $Q: Q$ is the average euclidean distance of a given day from its closest 33 analogs (Faranda et al., 2020). One can then compare $Q$ for the peak day of the extreme event to $Q$ for each analogue of the extreme event. If the value of $Q$ for the extreme event belongs to the same distribution as, or is smaller than, the values of $Q$ for the analogs, then the extreme event has good analogs and attribution can be performed. If instead the $Q$ for the extreme event is larger than that of the analogue days, then this indicates a highly unusual $s l p$ configuration and the results of the attribution analysis must be interpreted with care. Differences between the counterfactual and factual periods indicate whether the the atmosphere is visiting states (analogs) that are more or less similar to the map associated with the extreme (i.e. how large $Q$ for the peak day of the extreme event is), and whether those states are in turn more or less "typical" of the atmospheric variability (i.e. whether the distribution of $Q$ for the 33 analogs shifts towards higher or lower values).

- Seasonality of analogs: We can count the number of analogs in each month to detect whether there has been a shift of the circulation towards earlier or later months of the year. This can have strong thermodynamic implications, for example if a circulation leading to large positive springtime temperature anomalies becomes more common in summer, when average temperatures are much higher.

- Predictability Index D: Using dynamical systems theory (Freitas et al., 2011, 2016; Lucarini et al., 2016b), we can compute the local dimension $D$ of each daily slp map (Faranda et al. (2017b, 2019b), see Appendix A). The local dimension is a proxy for the number of degrees of freedom of the field, meaning that the higher $D$, the more unpredictable the temporal evolution of the $s l p$ maps will be (Faranda et al., 2017a; Messori et al., 2017). If the dimension $D$ of the chosen day is higher or lower than that of its analogs, then the day will be less or more predictable than the closest dynamical situations identified in the data. We compute two values of $D$ for the event, one using the counterfactual analogs and one using the factual ones. As for $Q$, we also compute the distribution of $D$ for all the analogs. This informs on how predictable the event is with respect to its analogs.

- Persistence Index $\Theta$ : Another quantity derived from the dynamical systems theory is the persistence $\Theta$ of a given configuration (Faranda et al. (2017b), see Appendix A). The persistence counts for how many days we are likely to observe a map that is an analogue of the one considered (Moloney et al., 2019). As explained for $Q$ and $D$, we compute the two values of the persistence for the event in the factual and counterfactual worlds and the corresponding distributions of persistence for the analogs. 


\section{Results}

Our list of 2021 extreme events is not intended to be exhaustive. We mostly cover Europe and North America, and we try to select events that differ in impacts, season and genesis in order to provide a rich overview of attribution capabilities and difficulties. We provide in Table 1 the list of the events studied, with the date for the analogs search, countries of interest and longitude-latitude box for the analogs search. A graphical representation of the events is provided in Figure 1.

\begin{tabular}{|l|l|l|l|}
\hline Event & Date & Countries & analogs Box \\
\hline Winter Storm Filomena & $09-01-2021$ & Spain & {$\left[15^{\circ} \mathrm{W}, 10^{\circ} \mathrm{E}, 30^{\circ} \mathrm{N}, 46^{\circ} \mathrm{N}\right]$} \\
\hline French Spring Cold Spell & $06-04-2021$ & France & {$\left[10^{\circ} \mathrm{W}, 30^{\circ} \mathrm{E}, 30^{\circ} \mathrm{N}, 70^{\circ} \mathrm{N}\right]$} \\
\hline Westphalia floods & $14-07-2021$ & Benelux/Germany & {$\left[5^{\circ} \mathrm{W}, 23^{\circ} \mathrm{E}, 41^{\circ} \mathrm{N}, 59^{\circ} \mathrm{N}\right]$} \\
\hline Mediterranean Heatwave & $11-08-2021$ & Spain/France/Italy & {$\left[10^{\circ} \mathrm{W}, 25^{\circ} \mathrm{E}, 30^{\circ} \mathrm{N}, 45^{\circ} \mathrm{N}\right]$} \\
\hline Hurricane Ida & $02-09-2021$ & USA & {$\left[80^{\circ} \mathrm{W}, 55^{\circ} \mathrm{W}, 35^{\circ} \mathrm{N}, 55^{\circ} \mathrm{N}\right]$} \\
\hline Po Valley Tornadoes Outbreak & $19-09-2021$ & Italy & {$\left[10^{\circ} \mathrm{W}, 20^{\circ} \mathrm{E}, 35^{\circ} \mathrm{N}, 50^{\circ} \mathrm{N}\right]$} \\
\hline Medicane Apollo & $29-10-2021$ & Italy & {$\left[10^{\circ} \mathrm{E}, 20^{\circ} \mathrm{E}, 34^{\circ} \mathrm{N}, 40^{\circ} \mathrm{N}\right]$} \\
\hline Scandinavian Cold Spell & $28-11-2021$ & Sweden/Norway & {$\left[10^{\circ} \mathrm{W}, 30^{\circ} \mathrm{E}, 35^{\circ} \mathrm{N}, 75^{\circ} \mathrm{N}\right]$} \\
\hline
\end{tabular}

Table 1. List of the events presented in this study, with the date for the analogs search, countries of interest and longitude-latitude box for the analogs search

\subsection{Winter Storm Filomena}

In early January 2021 the weather regime over the Euro-Atlantic sector was characterized by a negative phase of the North Atlantic Oscillation (NAO, see, e.g. Michelangeli et al. (1995)), with cold air from the Arctic being advected over southern Europe and frontal activity favoured over the Azores. Filomena was named after an extratropical cyclone that moved from the Azores to the Canary Islands and the Iberian Peninsula on the 6th and 7th of January respectively, resulting in strong precipitation and hurricane-force winds. It triggered historic snowfalls in the inland regions of the peninsula and a 14-days long cold spell. This exceptional event caused four casualties between the 9th and the 16th of January and economic losses of up to 2 billion euros (Aon, 2021). The storm formed on January 1st in the northeastern inland of the United States. On January 3rd it entered the North Atlantic and it began a sharp displacement southeastward forced by a high-pressure system in the central North Atlantic and pushed by a strong meridional polar jet. When it reached the Azores on the 5th, despite being weakened, it was finally named Filomena by the AEMET, which emitted a severe weather warning for Canary Islands and Spain for the two following days. The 6th and 7th of January, Filomena strengthened as it moved southeast towards the Canary Islands. The cyclone traveled northeastward towards the Iberian Peninsula on January 7th, bringing relatively warm, humid air for the Winter season. At this time, southern Europe was experiencing cold temperature anomalies because of an anticyclone located west of the UK, resulting in temperature minimums below $0^{\circ} \mathrm{C}$ in almost the entire Iberian Peninsula. Hence, when the 


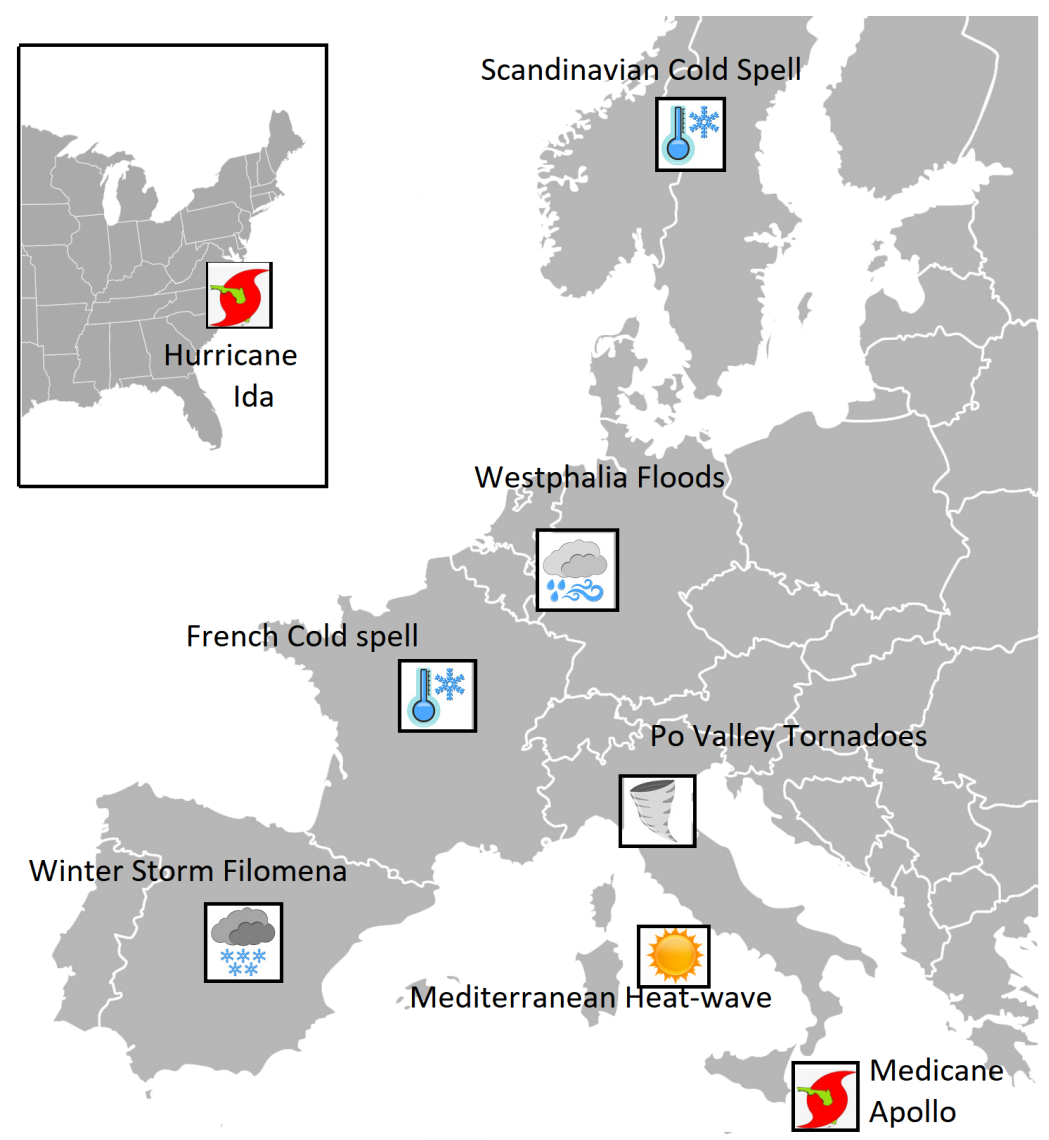

Figure 1. Visual representation of the events studied in this work.

storm arrived in the Gulf of Cadiz on January 8th, its warm front blew over the preexisting cold air, allowing precipitation in the form of snow or sleet throughout most of the Iberian Peninsula, except for some parts of southern Spain. The precipitation lasted for three days, until Filomena dissipated in the Mediterranean sea on January 11th. The most affected regions were central and northeastern Spain, which accumulated an average of 30 to $50 \mathrm{~cm}$ of snow (AEMET, 2021b). The accumulated snow favored the persistence of low temperatures in the following days, triggering a cold spell that lasted for about two weeks, from January 5th to 17 th, with a temperature average of $2{ }^{\circ} \mathrm{C}$ in the Iberian peninsula and an anomaly of $-3.8^{\circ}$ with respect to the 1981-2010 climatology, as recorded by the AEMET (2021b).

\subsubsection{Extratropical winter storms and climate change}

Numerous studies have addressed the influence of climate change on extratropical cyclones (ECT) due to their impacts on many regions of the planet (e.g. Zappa et al., 2013; Ulbrich et al., 2009). The IPCC report gathers and summarizes some of them (Lee et al., 2021) and it highlights that, by the end of the 21 st century, the number of extratropical cyclones will slightly 
decrease, especially in the southern flank of storm tracks. In the Southern Hemisphere, storm tracks are likely to shift poleward, while there is low confidence in the response in the Northern Hemisphere. CMIP6 models show a tripolar pattern in the North Atlantic storm track in winter, represented by an increase in storm activity over central Europe and a decrease in Scandinavia, Southern Europe, and the Mediterranean region (Lee et al., 2021). There is high confidence that the average precipitationrate of ETCs will increase in a future climate in response to the increase in the atmospheric water vapor content. Snowfall associated with ECTs will decrease because of tropospheric temperature increases (Seneviratne et al., 2021). According to Seneviratne et al. (2021), the number of ECT associated with strong winds over the North Atlantic and Europe will decrease. Hence, Filomena-like storms would be less probable in a future climate and would be less likely to produce such amounts of snowfall and strong winds, although they would be associated with more precipitation.

\subsubsection{Attribution of Filomena to climate change}

We now use the ERA5 data to perform the attribution of the cyclonic circulation associated with Filomena for the 09-01-2021 in the past and present climate (Figure 2). We find a significant decrease of the $s l p$ depression up to $3 \mathrm{hPa}$ for the factual with respect to the factual period (a-d). Temperatures (e-g) are significantly and considerably warmer (h) in the recent period, specially over land, probably due to a temporal shift of the recurrence of this storm towards warmer months and an increase in surface temperatures in recent years. This warming does not imply a general increase in the precipitation, hence we deduce that the precipitation changes are more dynamically induced. Precipitation (l) is significantly larger over southeastern Cantabrian Sea and Cape Nao, and lower in the Pyrenees, Catalonia and south of the Iberian Peninsula. However, no significant differences are found in the peninsular center, where Filomena had the highest impact. The analogs quality $Q(\mathrm{~m})$ shows that this circulation pattern is highly uncommon in both periods because the quality of the event lies at the edge of the violin plots. This suggests that Filomena is somehow a black swan (Taleb, 2005), an event that has not occurred before as its analogs are distributed in a different way. The predictability index $D(\mathrm{n})$ increases slightly in the factual world while the persistence $\Theta(\mathrm{o})$ decreases, which means that storms like Filomena are more predictable and less persistent in the current climate. We see an overall decrease in frequency in Spring and an increase in Summer months.

Hence, this event would have been colder and more likely in the counterfactual world, leading to even lower temperatures and higher precipitation on the Pyrenees. We underline that the fact that analogs quality $Q$ is poor for the event and that there are no analogs in the counterfactual nor factual world in January, make Filomena a black swan of the atmospheric circulation, an unprecedented event, emphasizing the exceptional nature of the event and the limitation of this and other attribution studies.

\subsection{French Spring Cold Spell}

A frost event took place from 6th to 8th April 2021 in France. It was exceptional, with daily minimum temperatures below $-5^{\circ} \mathrm{C}$ recorded in several places. Grapevines and fruit trees were damaged especially in the Loire and Rhône Valleys, as frost management strategies (e.g. as local heating from braseros) could not be implemented in time. The temperatures broke record lows at many French weather stations. This cold event happened one week after an episode of record-breaking high temperatures in March also in many places in France (LaChaineMeteo, 2021) and Western Europe. This sequence (or compound 

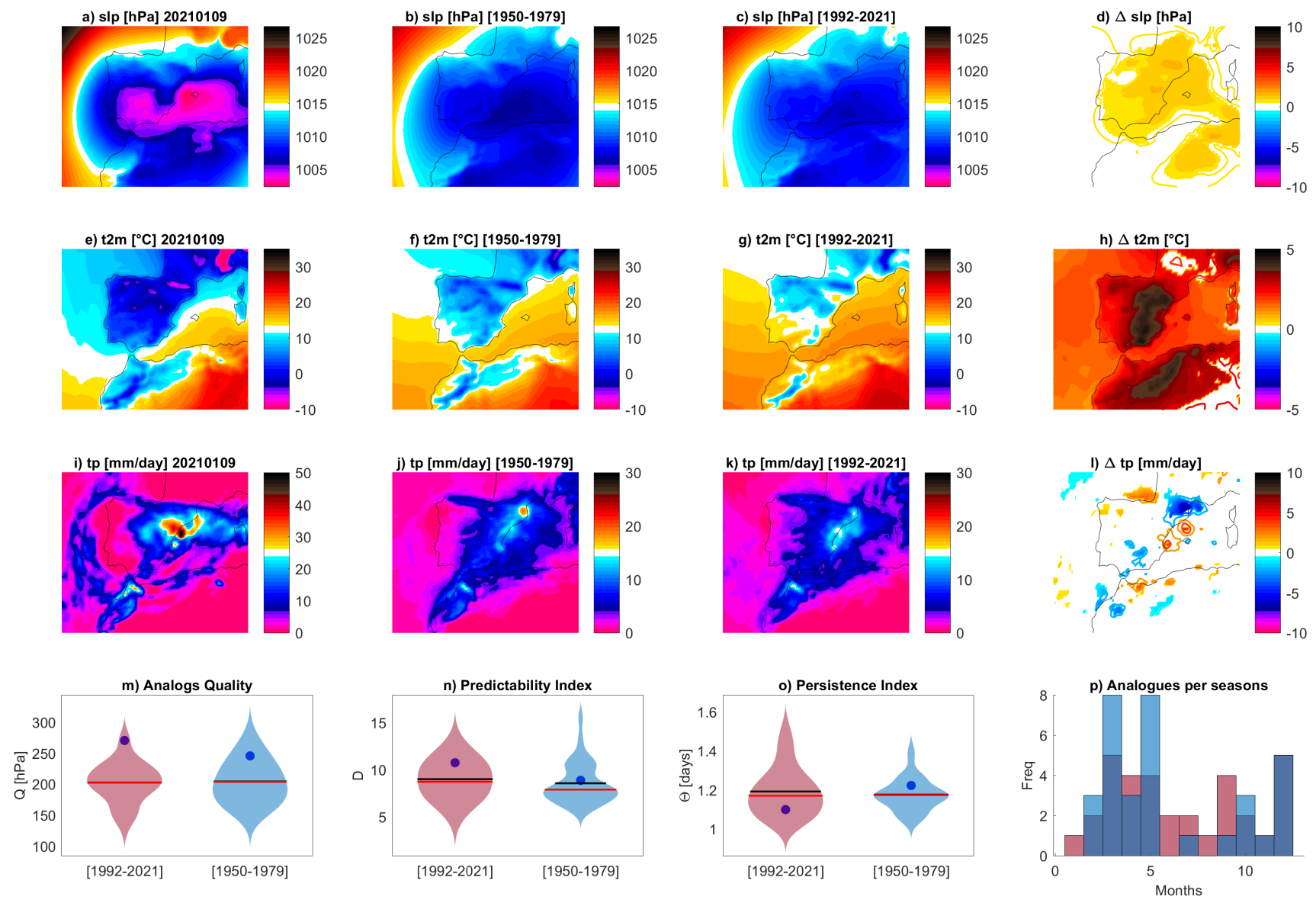

Figure 2. Attribution for Filomena Storm on 09-01-2021. Daily mean sea-level pressure $s l p$ (a), 2-meter temperatures $t 2 m$ (e) and total precipitation $t p$ (i) on the day of the event. Average of the 33 sea-level pressure analogs found for the counterfactual [1950-1979] (b) and factual [1992-2021] (c) periods and corresponding 2-meter temperatures (f,g) and daily precipitation rate (j,k). $\Delta s l p(\mathrm{~d}), \Delta t 2 m$ (h) and $\Delta t p$ (i) between factual and counterfactual periods: colored-filled areas show significant anomalies with respect to the bootstrap procedure. Violin plots for counterfactual (blue) and factual (pink) periods for the Analogs Quality $Q(\mathrm{~m})$ the Predictability index $D$ (n), the Persistence index $\Theta(\mathrm{o})$ and the distribution of analogs in each month (p). Values for the selected day are marked by a blue dot.

event, according to the definition proposed by Zscheischler et al. (2020)) led the growing season to start early, with bud burst occurring in March and the new leaves and flowers left exposed to the deep frost episode that followed in early April. This cold spell was associated with an advection of cold air from the Arctic into France between April 5th and 7th 2021. A deep low pressure based over Scandinavia and anticyclonic conditions overs Iceland, pumped cold Arctic air into France on April 5-6th 2021, which created the low-temperature anomaly in the subsequent days. 


\subsubsection{French cold spells and climate change}

The IPCC AR6 describes as "virtually certain" that there have been warmer and/or rarer cold spells over most land areas since the 1950s, that this trend is due to anthropogenic climate change and that it is set to continue in the future Allan et al. (2021). Indeed, there is a large consensus the frequency and average duration of such events will eventually decrease (Russo and Sterl, 2011).

While a rapid warming, in general, lowers the probability of cold spell occurrence, projected changes in the temperature distribution imply that regional changes in cold spell frequency and/or intensity may not match changes in the mean temperature (Tamarin-Brodsky et al., 2019). Similarly, Kodra et al. (2011) have shown that long-lasting periods where temperatures drop below an absolute threshold (e.g. frost days) may still be produced locally and occasionally even in future, warmer climates. There has also been a a lively debate in the literature on whether dynamical changes associated with climate change may act to partly counter the thermodynamic changes and favour cold spell occurrence. Faranda (2019) and D'errico et al. (2019) argued that circulation patterns associated with cold spells over Europe have been increasing in frequency in the present climate and will continue to do so under future climate change. Several authors have also argued for or against a link between Arctic Amplification and an increased occurrence of cold spells in some mid-latitude regions (Mori et al., 2014; Cohen et al., 2018; Blackport and Screen, 2020; Ye and Messori, 2020; Jolly et al., 2021).

Cold spells continue to have large detrimental socio-economic effects, with several high-impact events occurring in recent winters, notably during the 2018-2019 and 2020-2021 winters in North America (Lee and Butler, 2020; BBC; Lillo et al., 2021; Doss-Gollin et al., 2021; CNN) and the 2017-2018 winter in Europe (Kautz et al., 2020; LeMonde, 2018). Moreover, even if the absolute severity of cold spells decreases, rapid temperature swings are a hazard in their own right (Kral-O'Brien et al., 2019; Casson et al., 2019).

\subsubsection{Attribution of French cold spells to climate change}

A statistical analysis of the temperatures during the French cold spell of 2021 was proposed by a team of the World Weather Attribution (Vautard et al., 2021). This report concluded that while climate change has raised the absolute temperatures during cold spells, it has also led to an intensification of growing-period frosts due to earlier bud burst. The 2021 cold outbreak occurred right after a specific weather pattern called the "Atlantic Ridge", identified as one of the four main weather regimes in the North Atlantic region (Michelangeli et al., 1995). The goal of this section is to analyse how the features of this weather pattern have evolved with climate change using the ERA5 reanalyses (Figure 3). This analysis complements the report of Vautard et al. (2021) by examining the atmospheric circulation. We focus on the date of 06-04-2021, the day where the circulation particularly favored the advection of cold air into France. For this day the $s l p$ pattern (a) consists of a ridge of high pressure over the Atlantic and a large cyclonic structure over Scandinavia, with cold air advection from Northern latitudes into France. The analogs associated with this circulation in the counterfactual (b) and factual (c) exhibit the same zonal pressure gradient, and their difference (d) shows that the gradient is amplified in factual world, leading to colder advection towards France. The $t 2 m$ for the 06-04-2021 (e) shows cold conditions over Northern and Western Europe, while the analogs are 
milder (f,g) and $\Delta t 2 m$ is mostly everywhere greater than $0^{\circ} \mathrm{C}$. If we focus over France, we can conclude that this cold spell would have lead to temperature $2-4^{\circ} \mathrm{C}$ colder without anthropogenic forcing. Looking at the precipitation maps $(\mathrm{i}, \mathrm{j}, \mathrm{k})$ and the $\Delta t p$ (l) we see that this pattern corresponds to dry conditions over continental France. There is no change of precipitation patterns over France between the factual and counterfactual conditions. We observe that the atmospheric conditions triggers precipitation over continental and northern Europe. The reinforcement of the pressure gradient leads to an increase of the precipitation over continental Europe and a decrease on the Mediterranean sea. The values of $Q(\mathrm{~m})$ suggest that the pattern under examination is rare compared to its analogs, with a tendency to become even rarer in the factual period. The predictability index $D(\mathrm{n})$ tends to decrease in the factual period, While there are not significant shifts in the persistence $\Theta(\mathrm{o})$. The monthly distribution of the analogs (p) suggests that there is a significant shift of this circulation pattern towards summer and autumn months and that its occurrence in winter is decreasing in recent times.

To conclude, our analysis suggests, in line with the literature on cold spells and climate change cited in Section 4.2.1, that this event is becoming rare in the current climate and that it would have lead to cooler temperatures in a world without climate change.

\subsection{Westphalia floods}

On July 11th, 2021 the synoptic situation over Western Europe was characterized by a ridge situated West of Ireland. As this low-pressure system - named "Bernd" by the German Meteorological Service (DWD, see Junghänel et al. (2021)) - gradually moved eastward, it was isolated from the usually westerly flow by a strong anticyclonic system that built up over the Eastern part of the Atlantic and deviated the jet stream north of Scotland. By July 13th, Bernd was completely cut from the main flow and remained stationary over Western and Central Europe until July 16th, before being gradually pushed east. Hot and moist surface air from Northern Europe and the Mediterranean was advected by the cyclonic movement around the cut-off, which led from July 12th to July 15th to recurrent and persistent heavy rains first over mountain ranges due to orographic and dynamic uplift and then over the entire region of Belgium, Luxembourg, Western Germany and Eastern France. The maximum precipitations over the region were centered on the west of Belgium with some locations receiving more than $250 \mathrm{~mm}$ of rain in 48 hours (e.g. in Jalhay, Belgium, according to what reported by Kreienkamp et al. (2021)). The soils, already humid due to recurring precipitation events during the preceding three weeks, were incapable of absorbing more water which led to runoff and overflow of small watercourses and flash floods. Afterwards, larger rivers such as the Ruhr and the Meuse also overflowed, causing massive casualties mainly in Germany (196 people, according to DieWelt (2021)) and Belgium (42 casualties, according to HotNews.ro (2021)). In addition to the terrible fatalities, the floods severely damaged goods and infrastructures with a total cost estimated around $€ 10$ billion (Insurance) for Belgium. It was afterwards found using hydrological data that the flood in the regions affected was significantly higher than any flood since the beginning of the systematic records (Kreienkamp et al., 2021). 

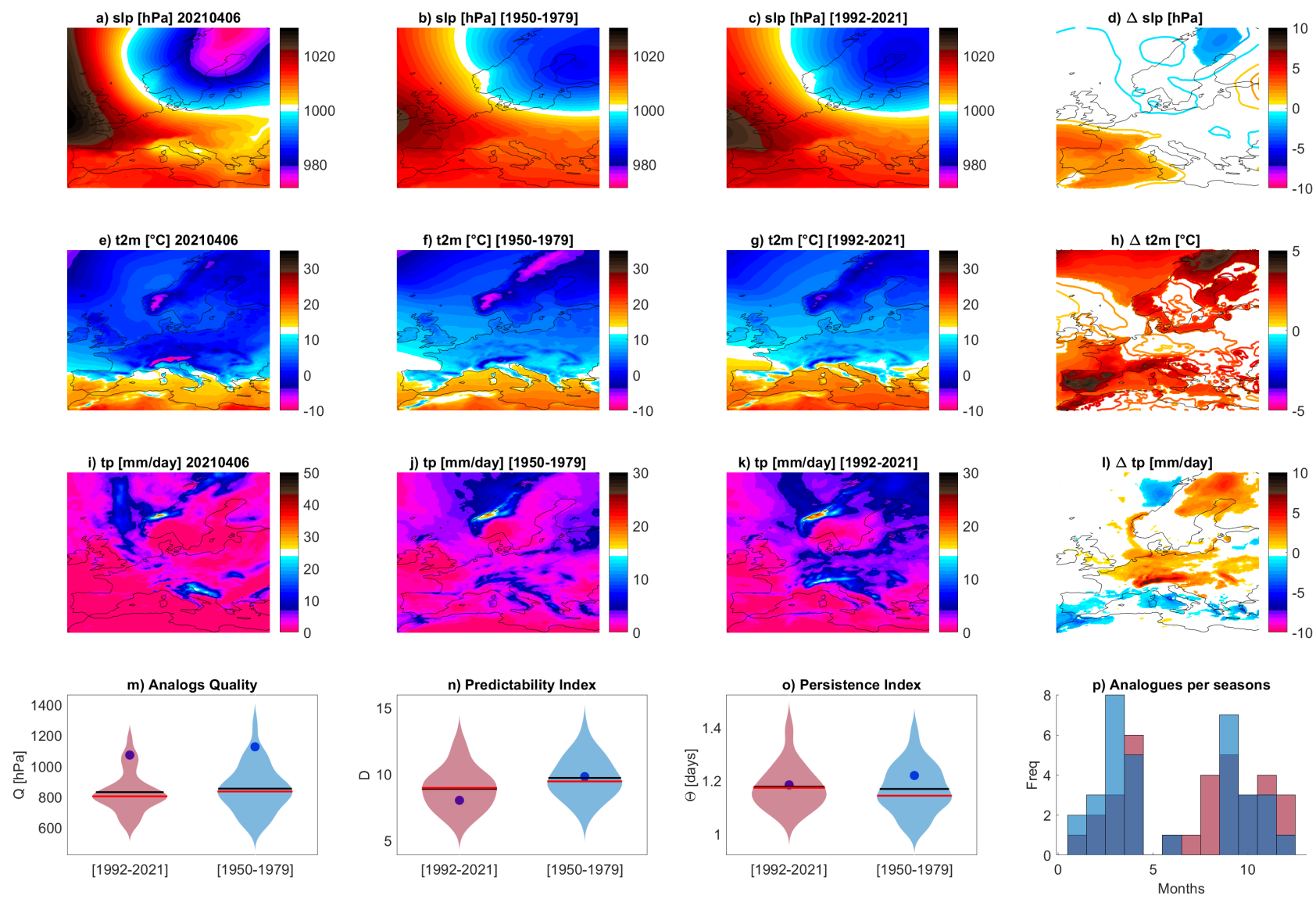

Figure 3. Attribution for the French cold spell on 06-04-2021. Daily mean sea-level pressure $s l p$ (a), 2-meter temperatures $t 2 m$ (e) and total precipitation $t p$ (i) on the day of the event. Average of the 33 sea-level pressure analogs found for the counterfactual [1950-1979] (b) and factual [1992-2021] (c) periods and corresponding 2-meter temperatures (f,g) and daily precipitation rate (j,k). $\Delta s l p(\mathrm{~d}), \Delta t 2 m(\mathrm{~h})$ and $\Delta t p$ (i) between factual and counterfactual periods: colored-filled areas show significant anomalies with respect to the bootstrap procedure. Violin plots for counterfactual (blue) and factual (pink) periods for the Analogs Quality $Q(\mathrm{~m})$ the Predictability index $D$ (n), the Persistence index $\Theta(\mathrm{o})$ and the distribution of analogs in each month (p). Values for the selected day are marked by a blue dot.

\subsubsection{Floods and climate change}

Rapidly after the event, the potential link between the event and climate change was highlighted by activists and journalists. Indeed, as the atmosphere warms up, it can contain more water - 7\% per degree of warming according to the Clausius-Clapeyron relationship - therefore allowing more powerful extreme precipitation events. Several studies (Madsen et al., 2014; Kundzewicz et al., 2018, 2019) investigated the link between climate variability, extreme precipitation and hydrological floods globally and in Europe. As stated in the last IPCC report (Allan et al., 2021) summarising scientific literature on the link between flooding 
events and anthropogenic climate change, there is high confidence that "a warmer climate will intensify very wet and very dry weather and climate events and seasons, but the location and frequency of these events depend on projected changes in regional atmospheric circulation." Especially for Europe, there is medium confidence that at $1.5^{\circ} \mathrm{C}$ of warming, "heavy precipitation and associated flooding are projected to intensify and be more frequent". This result highly depend on the type of water basins, especially if the peak flow is snowmelt-dominated, and more generally heavy precipitation are strongly entangled with natural variability of the climate system. In the end, although flooding usually depend strongly on the local characteristics of the hydrological system - especially artificialization of soils and containment of rivers - more intense flooding can be linked to climate change via the increased intensity of heavy rains.

\subsubsection{Attribution of Westphalia floods to climate change}

An attribution study of the Westphalia floods has already been published by the World Weather Attribution network, who investigated the influence of climate change on heavy precipitations over a broad region of Western Europe (Kreienkamp et al., 2021). The authors of the study concluded that a climate warming of $1.2^{\circ} \mathrm{C}$ (current climate) led to an increase of the likelihood of such an event by a factor between 1.2 and 9 with respect to the pre-industrial period. Here we take an approach based on analogs of the atmospheric circulation, which allows to take into account the atmospheric dynamics leading to the occurrence of the event. Results of our attribution analysis are displayed in Figure 4. We found a small significant decrease in the $s l p$ of the cut-off low over Germany by $2-3 \mathrm{hPa}$ (a-d) but almost no significant changes in the $2 \mathrm{~m}$ temperatures over the regions of interest (e-h). We found, however, a large and significant increase in precipitation (up to $5 \mathrm{~mm} /$ day) over south-west Germany, eastern France and western Alps (i-l). This increase is consistent with the increasing amount of water that a hotter atmosphere can carry but can also be explained by the increased advection of most air by the stronger cut-off over Germany. Overall, the analogs quality $(m)$ is good in both periods which reinforce our conclusions and allows us to emphasize that even if intense precipitation events due to cut-off lows over Western Europe in summer are not unusual, this event was particularly intense and climate change made it more intense. While no significant changes are observed for predictability $D(\mathrm{n})$, the persistence index $\Theta(\mathrm{o})$ is higher in the recent period, indicating that recent cut-offs are more likely to stay stationary in Western Europe, leading to longer lasting precipitation events and potentially more intense floods. In the factual period, events tend to happen more frequently in the month of July (p), a favorable month for the development of large convective systems in the area.

\subsection{Mediterranean Heatwave}

During the month of August, an area of high pressure in the upper troposphere affected a large part of the Mediterranean basin. The upper lever tropospheric pressure system caused a downward movement in the atmosphere that simultaneously compressed the air and warmed it, a phenomenon known as heat dome. This atmospheric configuration induced a severe heatwave over the Mediterranean region from August 10th to 15th: south Italy, France, Spain and north Africa were the area mostly affected with wildfires and maxima temperatures record. Indeed, under a high pressure system, the winds tend to be weak, so the heat does not dissipate and help to keep the conditions increasingly warmer especially with the summer sun heat. On August 11th, record-breaking temperatures were recorded at several locations in Italy. The town of Santa Maria Capua Vetere in Campania 

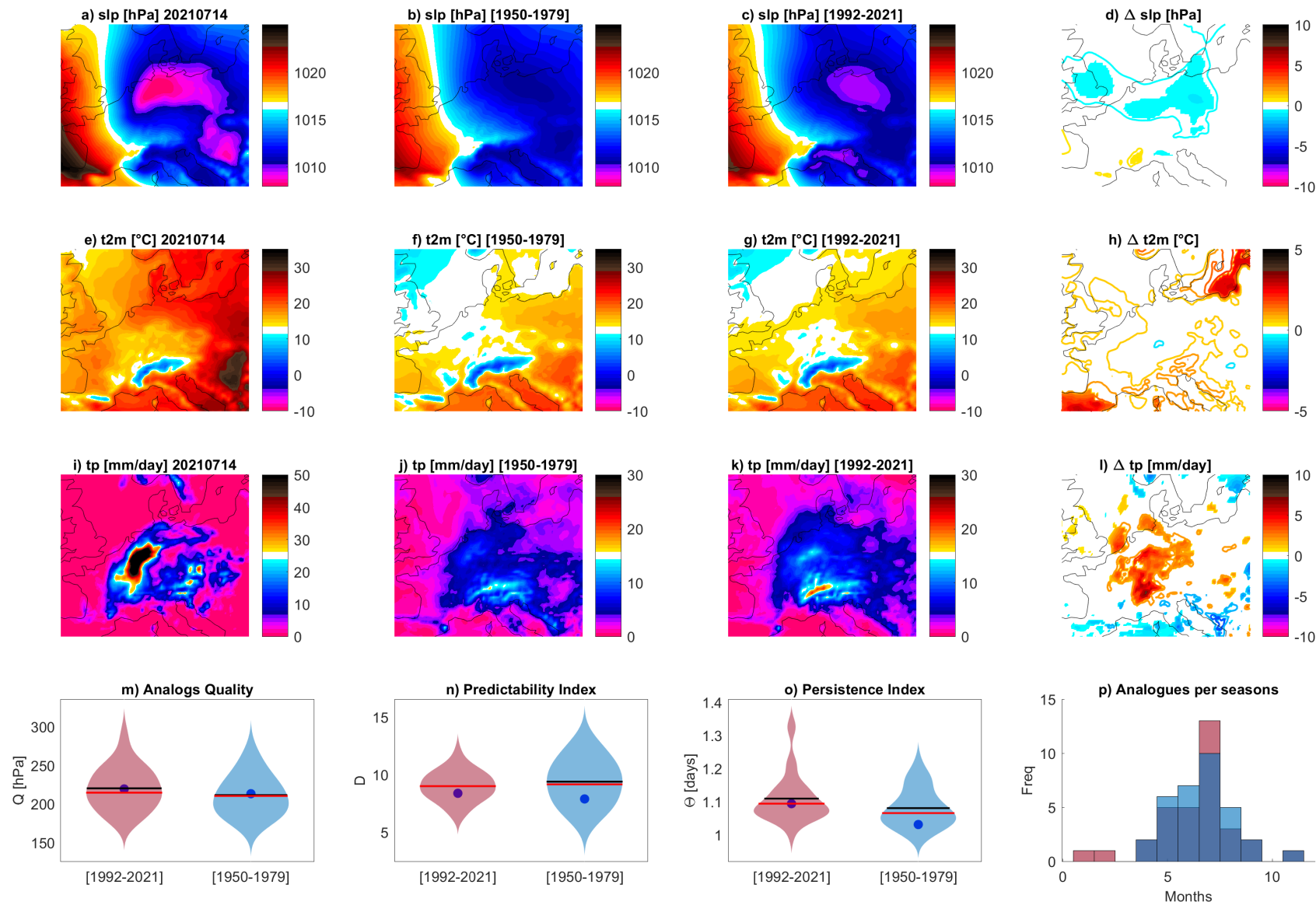

Figure 4. Attribution for the Westphalia Floods on 14-07-2021. Daily mean sea-level pressure $\operatorname{slp}$ (a), 2-meter temperatures $t 2 m$ (e) and total precipitation $t p$ (i) on the day of the event. Average of the 33 sea-level pressure analogs found for the counterfactual [1950-1979] (b) and factual [1992-2021] (c) periods and corresponding 2-meter temperatures (f,g) and daily precipitation rate (j,k). $\Delta s l p(\mathrm{~d}), \Delta t 2 m(\mathrm{~h})$ and $\Delta t p$ (i) between factual and counterfactual periods: colored-filled areas show significant anomalies with respect to the bootstrap procedure. Violin plots for counterfactual (blue) and factual (pink) periods for the Analogs Quality $Q(\mathrm{~m})$ the Predictability index $D$ (n), the Persistence index $\Theta(\mathrm{o})$ and the distribution of analogs in each month (p). Values for the selected day are marked by a blue dot.

reached $42.2^{\circ} \mathrm{C}, 44.5^{\circ} \mathrm{C}$ at Bova in Calabria and $43.6^{\circ} \mathrm{C}$ at Ballao in Sardinia (3Bmeteo, 2021). The highest temperature was recorded in eastern Sicily with a peak of $48.8^{\circ} \mathrm{C}$ recorded by the SIAS (2021) in Floridia in the province of Syracuse. This value represents the highest value recorded in Italy and Europe. From August 12th the heat dome moved towards Spain. The heat peak was reached on August 14th for Spain, establishing a new national record of $47.4^{\circ} \mathrm{C}$ in Montoro, Andalusia, as recorded by the AEMET (2021a). The heatwave also reached south-east France, where $40.9^{\circ} \mathrm{C}$ were recorded in Varages in the Var, and in Trets, Bouches-du-Rhône $\left(41.2^{\circ} \mathrm{C}\right)$. Same records were broken also in Tunisia, with $47^{\circ} \mathrm{C}$ in Tunis and $50.3^{\circ} \mathrm{C}$ in Kairouan (WMO, 2021). The heatwave also triggered a large spread of wildfires in Italy, Spain, France and Greece. During 
the night of August 11th to 12th, more than 500 fires were recorded in Italy, causing 4 casualties (CEMS, 2021c). Spain also faced flames in the area of Navalacruz and Riofrio. A fire of $90 \mathrm{~km}$ of perimeter devastated 12000 hectares of vegetation and led to the evacuation of 1000 inhabitants (CEMS, 2021a). Similarly in the Var (France) wildfires burned 6300 hectares and resulted in the evacuation of 7000 people and the death of 2 people (CEMS, 2021b).

\subsubsection{Mediterranean Heatwaves and climate change}

August is known as a hot and dry month in the Mediterranean region. However, the temperatures observed this summer are extreme and are typical of what is expected from climate change. In fact, according to the IPCC's Sixth Assessment Report AR6 (Allan et al., 2021), as a result of climate change, we are experiencing more frequent and severe high temperature events, and that this trend will continue in the future. It indicates that the frequency and intensity of heat extremes, including marine heatwaves, have increased in recent decades and are projected to continue to increase under all greenhouse gas emission scenarios. Temperatures in the Mediterranean region have increased more than the global average (Allan et al., 2021). The IPCC claimed that, for the European Mediterranean, there will be a combination of changes related to climate drivers ( e.g. less precipitation and snow, changes in the sea levels mean and extremes) by mid-century and for global warming of at least $2{ }^{\circ} \mathrm{C}$ and greater (high confidence). For the North African Mediterranean, the IPCC predicts a decrease in mean precipitation and increase in fire-related weather, as well as an observed and projected increase in aridity, meteorological, hydrological, agricultural and ecological droughts (Allan et al., 2021).

\subsubsection{Attribution of the Mediterranean Heatwave to climate change}

We use the ERA5 dates to perform the attribution of the anticyclonic circulation associated with the Mediterranean heatwave in past and present climate. First, we note that we will select the analogs independently of the extratropical or tropical nature of the depression that produced them. Figure 5 shows the results for the heatwave over Sicily. We do not detect a significant change in the $s l p$ for the factual period compared to the counterfactual period (a-d). However, we observe that temperatures (e-g) are significantly warmer $(\mathrm{h})$ in the recent period, especially over the island and the southern Mediterranean basin. This warming is associated with a significant decrease in precipitation in the factual period, especially in southern Europe, that could be explained by the high temperature and stability which suppress convection (i-1). We detect remarkable changes in the predictability index $D(\mathrm{n})$, which means that the $s l p$ pattern tends to be more unpredictable in the present time, and we find a slight decrease in the persistence $\Theta(o)$. Finally, we notice that the number of analogs per season is increasing in the factual period, in June and September $(\mathrm{m})$.

In summary, our analysis is perfectly in line with the existing literature cited in Section 4.4.1, as it shows the large predominance of the thermodynamic effects of climate change with a clear warming signal, higher on the area than the global average. This signal is associated with dryer conditions over land and an extension of this circulation patterns towards the beginning and the end of summer. 

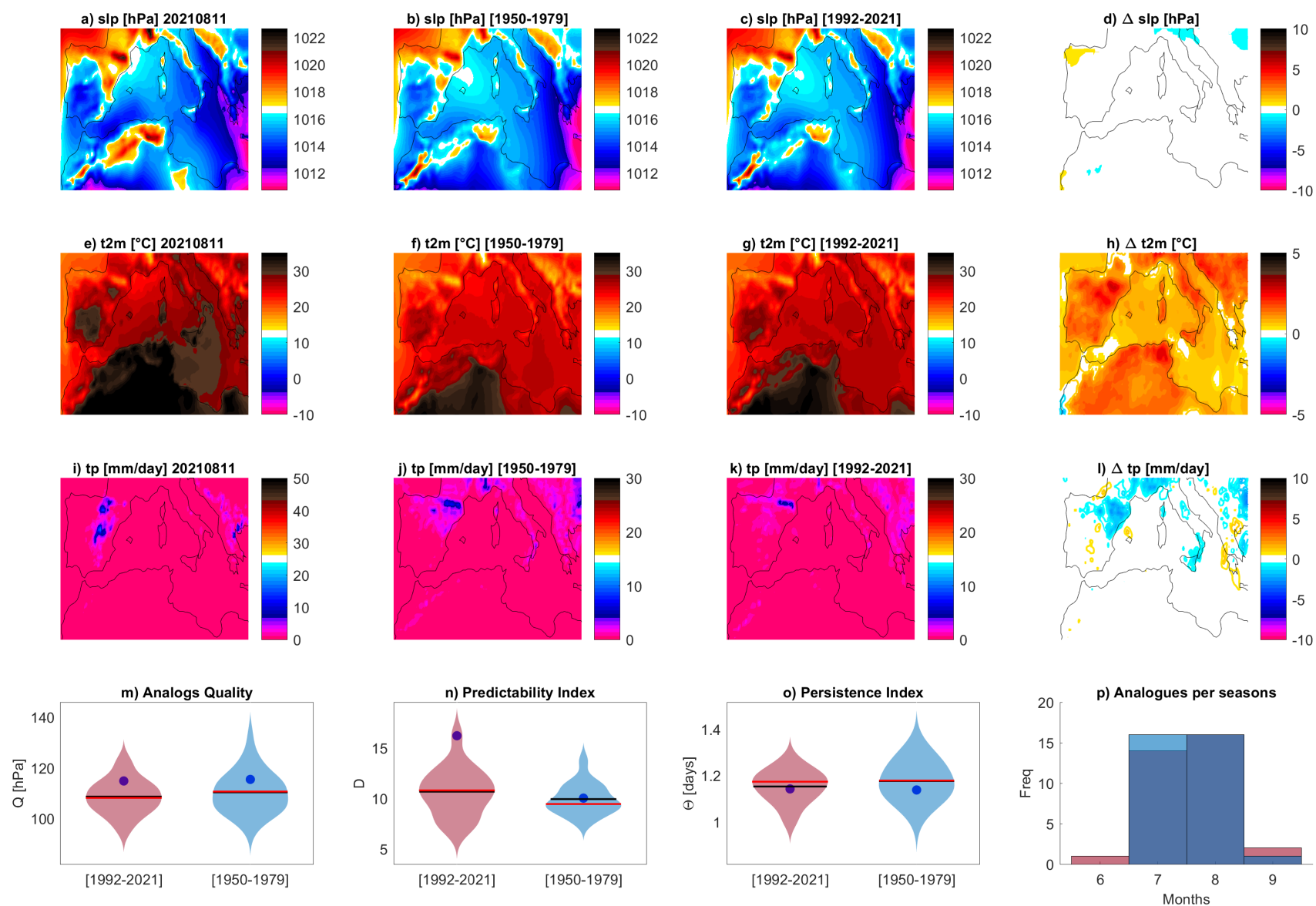

Figure 5. Attribution for the Mediterranean Heat Peak on 11-08-2021. Daily mean sea-level pressure $s l p$ (a), 2-meter temperatures $t 2 m$ (e) and total precipitation $t p$ (i) on the day of the event. Average of the 33 sea-level pressure analogs found for the counterfactual [1950-1979] (b) and factual [1992-2021] (c) periods and corresponding 2-meter temperatures (f,g) and daily precipitation rate (j,k). $\Delta s l p(\mathrm{~d}), \Delta t 2 m(\mathrm{~h})$ and $\Delta t p$ (i) between factual and counterfactual periods: colored-filled areas show significant anomalies with respect to the bootstrap procedure. Violin plots for counterfactual (blue) and factual (pink) periods for the Analogs Quality $Q(\mathrm{~m})$ the Predictability index $D$ (n), the Persistence index $\Theta(\mathrm{o})$ and the distribution of analogs in each month (p). Values for the selected day are marked by a blue dot.

\subsection{Hurricane Ida}

Hurricane Ida is a tropical and post-tropical cyclone event that occured in the North Atlantic basin (Caribbean Sea Mainland USA) in August-September 2021. Besides being the most intense TC to make landfall in the US this season, it had a very damaging post-tropical stage. Hurricane Ida (track shown in Figure 6) was first detected as a tropical wave on August 23th. It was named as a tropical storm on August 26th and it became a Category 1 Hurricane on the day it made a first landfall over Cuba on August 27th. This landfall did not weaken it, and it underwent rapid intensification as it approached Louisiana's 


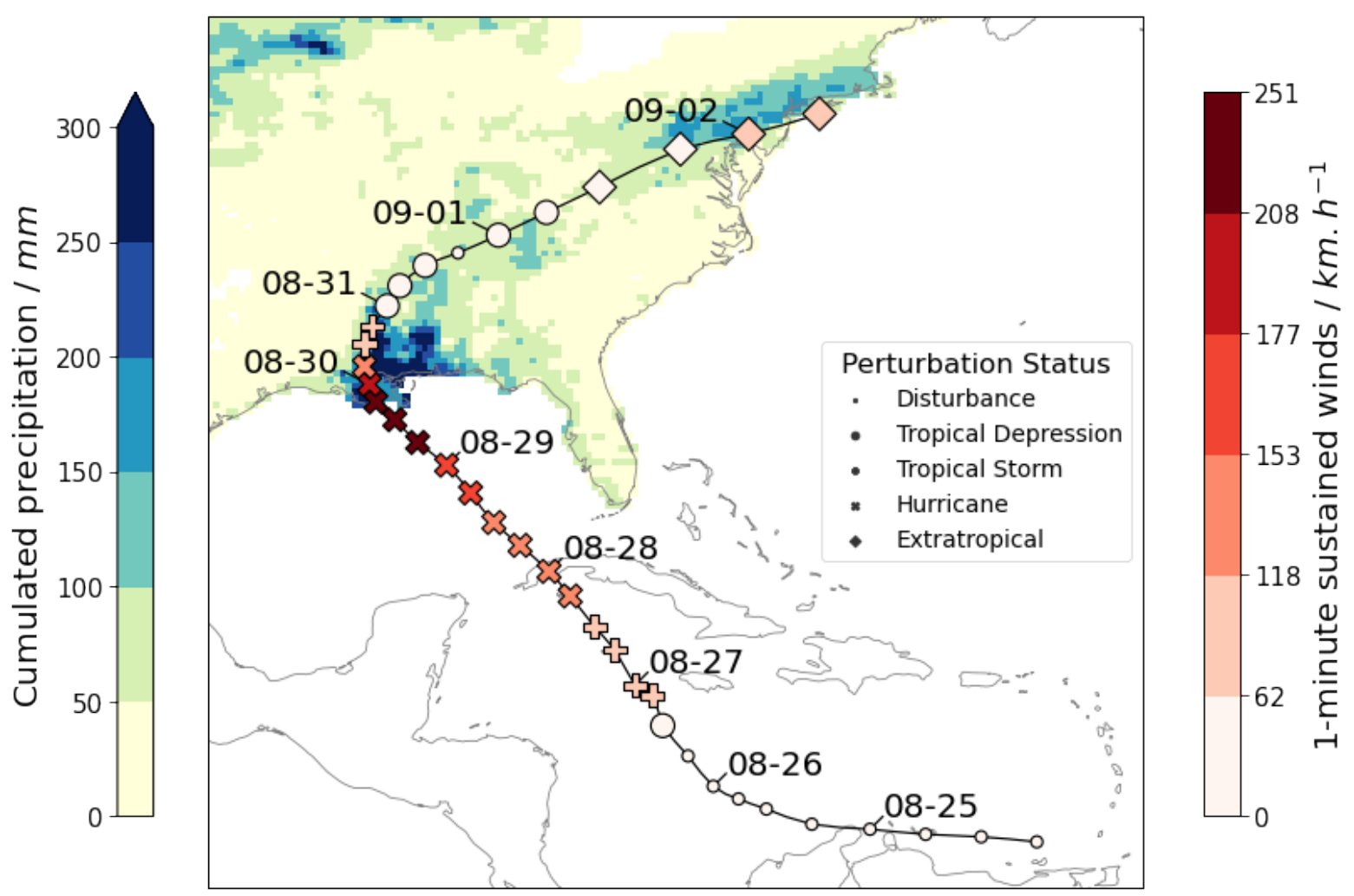

Figure 6. Track and associated precipitation for the Ida hurricane. 6-hourly track position from the IBTrACS (Knapp et al., 2010; Knapp, Kenneth R et al., 2018)) database are provided with their wind speed an status from NHC report. Time stamps are UTC, format mm-dd. Cumulated daily precipitation between 28-08-2021 and 03-09-2021 from the NCEP/CPC US Unified Precipitation are displayed. White color indicates no data in the figure

coast, were it landfell again as a Category 4 hurricane (NHC/NOAA, 2021). At its peak intensity, 1-minute sustained winds reached $240 \mathrm{~km} / \mathrm{h}$ and the minimum central pressure was $929 \mathrm{hPa}$. Notably, it did not rapidly weakened because of the "brown ocean effect", where flat and moist land conditions allow a TC to retain its intensity for a longer period of time. Ida finally dropped below hurricane strength on August 30th. While it was still a tropical wave, Ida triggered floods in Venezuela with 20 casualties. in Cuba, the material damage was important, but no casualties were reported. In Louisiana and Mississippi there were a total of 38 deaths, among which 23 indirect, mostly for CO poisoning (CDC, 2021). A large power outage left more than 1 million people in black-out. Heavy infrastructural damage is estimated around \$15 billion (NCDC/NOAA, 2021). These figures can be compared to Katrina's - the costliest hurricane to date, that made landfall on the same date and the same place 16 years before -1838 deaths and $\$ 125$ billion damages (NHC/NOAA, 2018). It shows that New Orleans was better prepared, and the forecast improved a lot as well (NHC/NOAA, 2005). While Ida was degenerating into an extratropical low, it combined with a frontal zone regaining tropical-storm force winds, and unleashing large amounts of rainfall over Northeastern US. This 
region was much less prepared, so that the casualties were greater than the tropical stage with 42 deaths, mostly because of the flash floods. Finally, Ida ended its course over Eastern Canada, dissipating in the Gulf of St Lawrence.

\subsubsection{Hurricanes and climate change}

Among all extreme events, tropical cylones (TC) are among those for which the prediction of the evolution with climate change is the most uncertain. This the reasons for this is threefold: (i) The lack of a satisfying theory for cyclogenesis, (ii) the shortspan of reliable observations, and (iii) the difficulty to simulate TC in state-of-the-art global models, because of their too coarse resolution. Despite the relatively short span of observation available, some conclusions can still be drawn from the past record (Knutson et al., 2019). Because of different trends in different regions, it is impossible to conclude on a global trend in TC frequency, but IPCC's AR6 (Allan et al., 2021) note that "it is likely that the global proportion of major TC occurrence has increased over the last four decades." Moreover, the latitude of the peak intensity shifted poleward (Kossin et al., 2014). Heavy precipitation associated with TC is also increasing with high confidence. Damages have been increasing, because of a larger amount of exposed wealth, but also a decrease in TC translation speed (Kossin, 2018). In the future, modeling studies using different methodologies (large-scale indicators vs. direct TC tracking) disagree on the sign of a global TC frequency trend. But there is confidence in trends of TC-related risks. Knutson et al. (2020) highlight consequences in order of certainty: i) because of sea-level rise, storms surges will become more important; ii) TC precipitation rates will increase, iii) The proportion of intense TC among all TC will continue to rise, and the maximum surface wind speed will increase of about 5\%.

There is also growing concern about the increase in windstorm risks associated with post-tropical cyclone (Haarsma, 2021). Indeed, studies in reanalyses showed that despite representing a small number of extra-tropical storms, post-tropical cyclones are among the most intense ones to reach North America and Europe (Baker et al., 2021; Sainsbury et al., 2020). A global climate change projection show that more tropical cyclones are likely to undergo post-tropical transition, especially in the North-Atlantic basin (Michaelis and Lackmann, 2019).

\subsubsection{Attribution of Hurricane Ida to climate change}

We now focus on the day Ida produced heavy precipitation in New-York city, namely the 02-09-2021 and apply the analogs methodology to perform attribution. First of all, let us note that we will select analogs independently on the extratropical or tropical nature of the depression that have produced them. Figure 7a) shows the daily $s l p$ associated with Ida on the chosen date and (b) and (c) the analogs average computed for the counterfactual and the factual periods. We find a significant weakening of the $s l p$ depression for the factual with respect to the factual period (d). Furthermore, we observe that temperatures (e-g) are significantly warmer (h) in the recent period especially on the sea grid-points surrounding the North-East US and Nova Scotia. This warming is associated with a significant increase of precipitation in the factual period due to the larger availability of heat and humidity (i-1). We have confidence in these results because the quality of the analogs $Q$ for the event is in the bulk of the distribution of $Q$ for its analogs in both factual and counterfactual periods (m). We do not observe shift in $D$ (n) or in $\Theta$ (o) in the factual vs counterfactual period. Finally we do see an increase of analogs in the month of August/September in the factual 
period (p): these months are at in the tropical cyclone season in the North Atlantic and therefore similar patterns could trigger deep convection in association with cyclonic depressions, leading to extreme precipitations as observed in the case of Ida.

Ida was already a rare extreme event as a category 4 hurricane, but it will leave a mark especially because of its impactful post-tropical stage. As we have discussed in Section 4.5.1, very intense hurricanes will become more frequent with climate change, and they will be more likely to undergo post-tropical transition. What is particular for Ida, however, is that this transition occurred inland. What allowed the storm to remain intense in between a very strong tropical cyclone stage and the encounter with an extra-tropical perturbation could be the wet and warm condition allowing for the "brown effect". Such conditions are expected to be more likely with climate change. However, no formal study of such inland post-tropical cyclones have been made that we are aware of. While our attribution does not take into account the tropical/extratropical nature or the direction of the storm, we believe that the seasonal shift of the analogs towards late summer together with the temperature increase in the Atlantic in the factual world provides a solid explanation of the potential danger of this kind of events in the present climate.

\subsection{Po Valley Tornadoes Outbreak}

On September 19, 2021, an outbreak of 7 tornadoes affected the Central Po Valley, in Northern Italy. In particular, 6 of these formed in Lombardy and one, the most intense and damaging, hit a small airport near Carpi, Emilia Romagna. Both mesocyclonic and non-mesocyclonic vortices were observed during the event, making it one the most impressive tornado outbreaks on record for the region. While tornadoes and waterspouts happen regularly in Italy, they are on average much less frequent and less intense than in highly affected areas, such as the Mid-Western and South-Eastern US. However, the structure and location of the Po Valley can lead to the insurgence of environmental conditions conducive for occasionally intense phenomena, including tornadoes reaching EF4+ intensity on the Enhanced Fujita scale (Doswell III et al., 2009). During the summer, the Po Valley can be characterized by the persistence of hot and humid air, and the presence of the Adriatic Sea to the South-East provides an additional source of moisture, which can be advected to the region by low-level jets preceding low pressure areas approaching from the North-West. Moreover, the presence of the Appennini can encourage the formation of dry lines in case of South-Westerly flow due to foehn effect, contributing to supercell development (Alberoni et al., 1996). On September 19th, a high pressure system was elevated from the Central Mediterranean Sea to Scandinavia, while a high-level low pressure was approaching the Po Valley from France, connected to a trough located over North-Western Europe. During the afternoon, the region was affected by a favourable dynamic and thermodynamic setup: a hot and humid low-level jet from the East, a strong wind shear with winds from the South-West at $500 \mathrm{hPa}$, a jet stream from the West at $200 \mathrm{hPa}$, and an approaching upper-level low characterized by relatively cold air, and by the entrainment of stratospheric dry air. This led to the formation of strong thunderstorms associated with 6 tornadoes over Lombardy, roughly between the cities of Milan and Brescia. Around $5 \mathrm{pm}$, an isolated thunderstorm formed to the South-East of this area, closer to the Appenninic range, and assumed markedly supercellular features, with a hook-echo reflectivity signature, a doppler velocity couplet and a deviation to the right w.r.t. the mid-level flow. This supercell produced a well-documented significant tornado which hit a local airport, resulting in possible EF3 damage (Poli and Stanzani, 2022). 

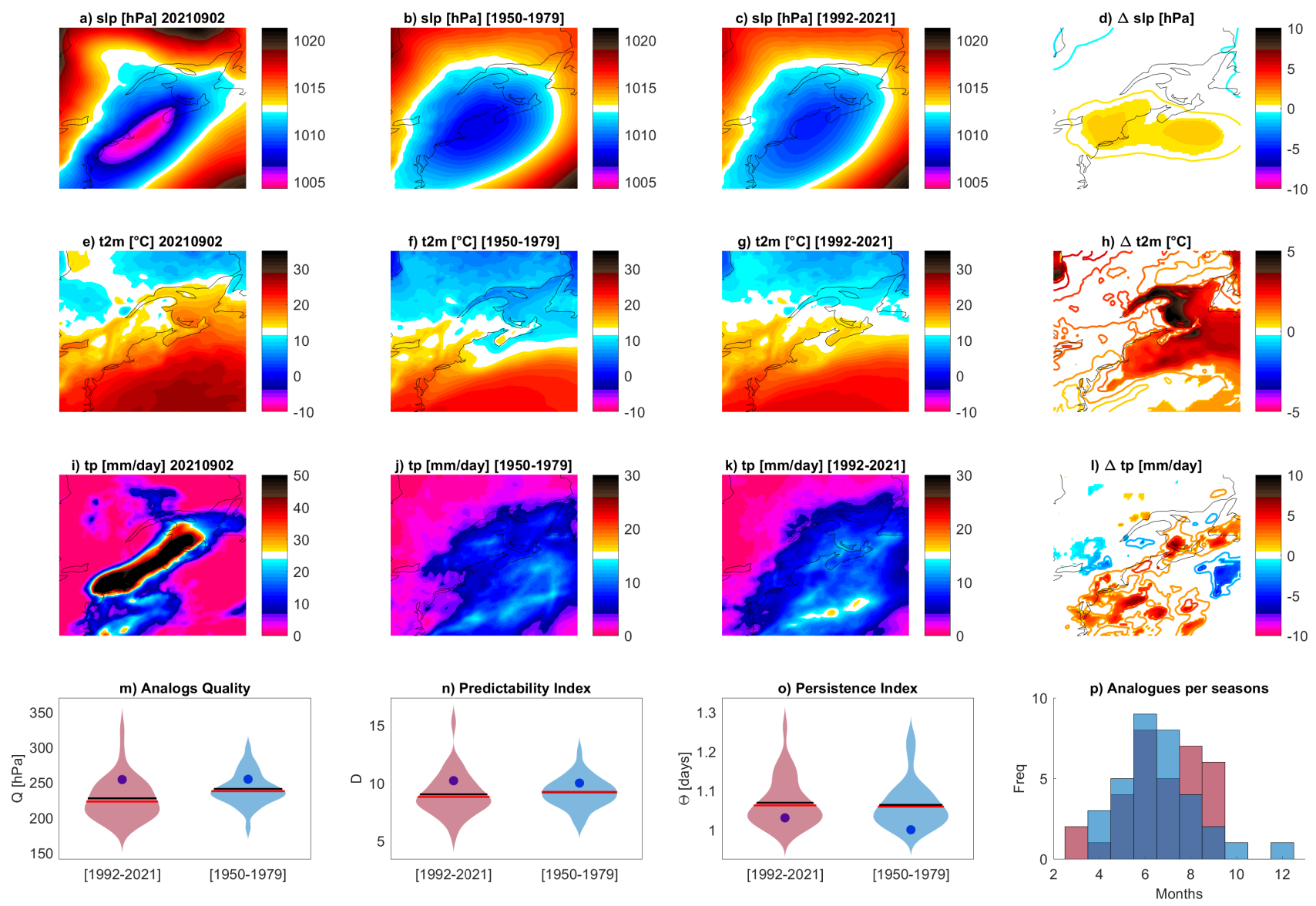

Figure 7. Attribution for the Hurricane Ida passage over New-York City area on 02-09-2021. Daily mean sea-level pressure $s l p$ (a), 2meter temperatures $t 2 m$ (e) and total precipitation $t p$ (i) on the day of the event. Average of the 33 sea-level pressure analogs found for the counterfactual [1950-1979] (b) and factual [1992-2021] (c) periods and corresponding 2-meter temperatures (f,g) and daily precipitation rate $(\mathrm{j}, \mathrm{k}) . \Delta s l p(\mathrm{~d}), \Delta t 2 m(\mathrm{~h})$ and $\Delta t p$ (i) between factual and counterfactual periods: colored-filled areas show significant anomalies with respect to the bootstrap procedure. Violin plots for counterfactual (blue) and factual (pink) periods for the Analogs Quality $Q$ (m) the Predictability index $D(\mathrm{n})$, the Persistence index $\Theta$ (o) and the distribution of analogs in each month (p). Values for the selected day are marked by a blue dot.

\subsubsection{Tornadoes and Climate Change}

Past and future trends in tornado occurrence have been the object of investigation in several studies, summarised in the IPCC AR6 (Allan et al., 2021). In particular, the IPCC reports that observed trends in tornado occurrence are associated with low confidence, due to short time series, reporting inhomogeneity and observation bias; low confidence affects also the estimation of future trends, due to the intrinsic difficulty associated with projections of small-scale convective extremes. However, medium 
confidence is given to a tendency of tornadoes to be clustered in less frequent but more efficient outbreaks, characterized by a higher number of tornadoes per episode, with a total tornado number approximately constant over time. High confidence is given to the projected increase in frequency of environments conducive for the formation of tornadoes. Finally, it is concluded that attribution efforts for this phenomenon are beyond current modelling capabilities (Allan et al., 2021). Most studies are focused on the US, pointing to an increased variability, efficiency and possibly intensity of tornado outbreaks (Brooks et al., 2014; Elsner et al., 2015, 2019); however, tornadoes in Europe remain an underestimated threat (Antonescu et al., 2017), even though they can interest very densely populated areas, as in the case described in this article.

\subsubsection{Attribution of the Po-Valley Tornadoes Outbreaks to climate change}

We conclude by using the ERA5 dates to perform the attribution of the synoptic configuration associated with the outbreak in the past and present climate. Figure 8 shows the results for the episode. We find a significant but modest and unstructured increase of the $s l p$ field for the factual with respect to the counterfactual period (a-d). Instead, we observe that temperatures $(\mathrm{e}-\mathrm{g})$ are significantly warmer $(\mathrm{h})$ in the recent period, both over land and the Mediterranean sea. This provides an increased amount of convective potential energy, though the transport of hot and humid air within the low-level jet. Precipitations associated with this configuration are higher over the Alps and Central Europe, while slightly lower over the Italian peninsula (i-1). The analogs quality shows that this circulation pattern is common compared to the rest of the analogs. We do not detect visible changes in the predictability $D(\mathrm{n})$ and persistence $\Theta$ (o) of the configuration. Finally, we observe that the seasonal occurrence of analogs ( $\mathrm{p}$ ) is quite consistent with the months of occurrence of tornadoes in the country, with a maximum during summer; however, we do observe a shift of the peak from August to July, when land surface temperatures reach the annual maximum and the probability of low pressure areas entering the Mediterranean basin is higher than in May or June, offering more energy and occasions for convective instability.

Concerning the impact of climate change on the occurrence of tornado outbreaks, our analysis shows a clear increase in temperature associated to the analogs of this event in the factual period 1992-2021. This is compatible with the enhancement of thermodynamic setups due to climate change mentioned in Section 4.6.1, leading to more favourable environments for tornadoes. However, the small spatio-temporal scale of the phenomenon require caution in the interpretation of the attribution results.

\subsection{Medicane Apollo}

When the relatively cold atmospheric air coming from polar latitudes meets the warm surface of the Mediterranean Sea, extratropical cyclones change their characteristics into near-tropical depressions. These hybrids - termed "medicanes" (crasis for Mediterranean Hurricanes) by climate scientists and meteorologists - can be very damaging because of the strong winds and the intense convective precipitations (thunderstorms) originating around the eye of the storm. Medicane Apollo (named by a consortium of European meteorological services, see Meteoweb (2021)) formed on October 28th in the Jonian sea, offshore Sicily, from a low pressure disturbance which was very active in the days previous the formation of the Medicane. This low pressure system was isolated near the Balearic islands around 22nd of October and then moved on the Central Mediterranean 

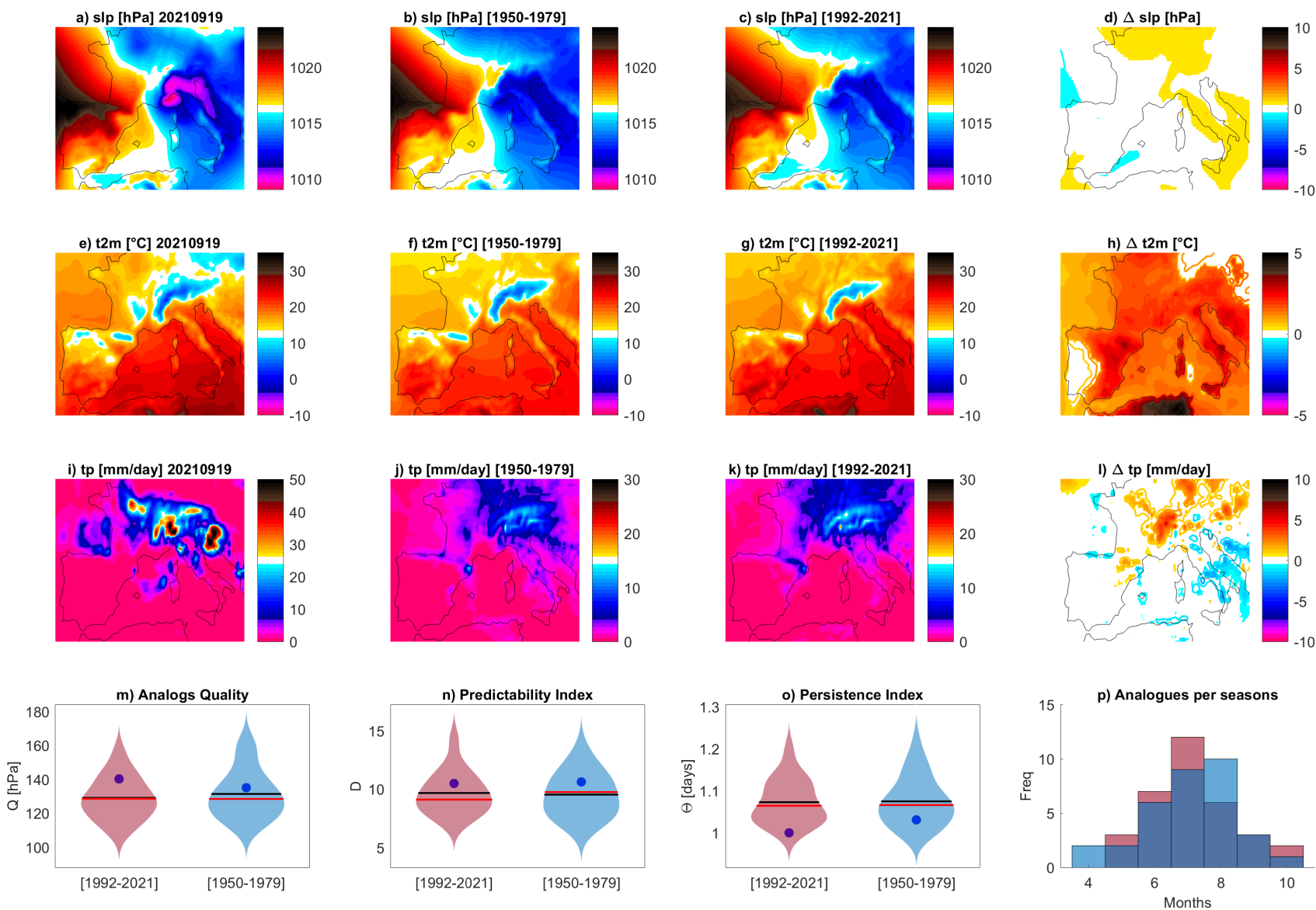

Figure 8. Attribution for the Po Valley Tornadoes Outrbreak on 19-09-2021. Daily mean sea-level pressure $s l p$ (a), 2-meter temperatures $t 2 m$ (e) and total precipitation $t p$ (i) on the day of the event. Average of the 33 sea-level pressure analogs found for the counterfactual [1950-1979] (b) and factual [1992-2021] (c) periods and corresponding 2-meter temperatures (f,g) and daily precipitation rate (j,k). $\Delta s l p$ (d), $\Delta t 2 m$ (h) and $\Delta t p$ (i) between factual and counterfactual periods: colored-filled areas show significant anomalies with respect to the bootstrap procedure. Violin plots for counterfactual (blue) and factual (pink) periods for the Analogs Quality $Q$ (m) the Predictability index $D(\mathrm{n})$, the Persistence index $\Theta(\mathrm{o})$ and the distribution of analogs in each month (p). Values for the selected day are marked by a blue dot.

sea producing self-regenerating thunderstorms in the area of Catania on the 24th of October. Figure 9 displays the track of

the cyclone along its life-cycle. These thunderstorms resulted in extreme rain and floods in Catania ( $>400 \mathrm{~mm}$ rain in $48 \mathrm{~h}$, estimated by SIAS (2021)). During the tropical phase of Apollo, according to the latest report available, at least 10 people were killed by the storm in Sicily, Malta, Algeria and Tunisia (jbarisk, 2021). The highest wind gusts were measured on October 29th $(104 \mathrm{~km} / \mathrm{h})$ and the pressure minimum value was estimated to $999 \mathrm{hPa}$. From the convective precipitations associated with Apollo, the Sicilian Meteorological service SIAS measured $>200 \mathrm{~mm}$ rain in the area of Syracuse on the same date. Apollo 

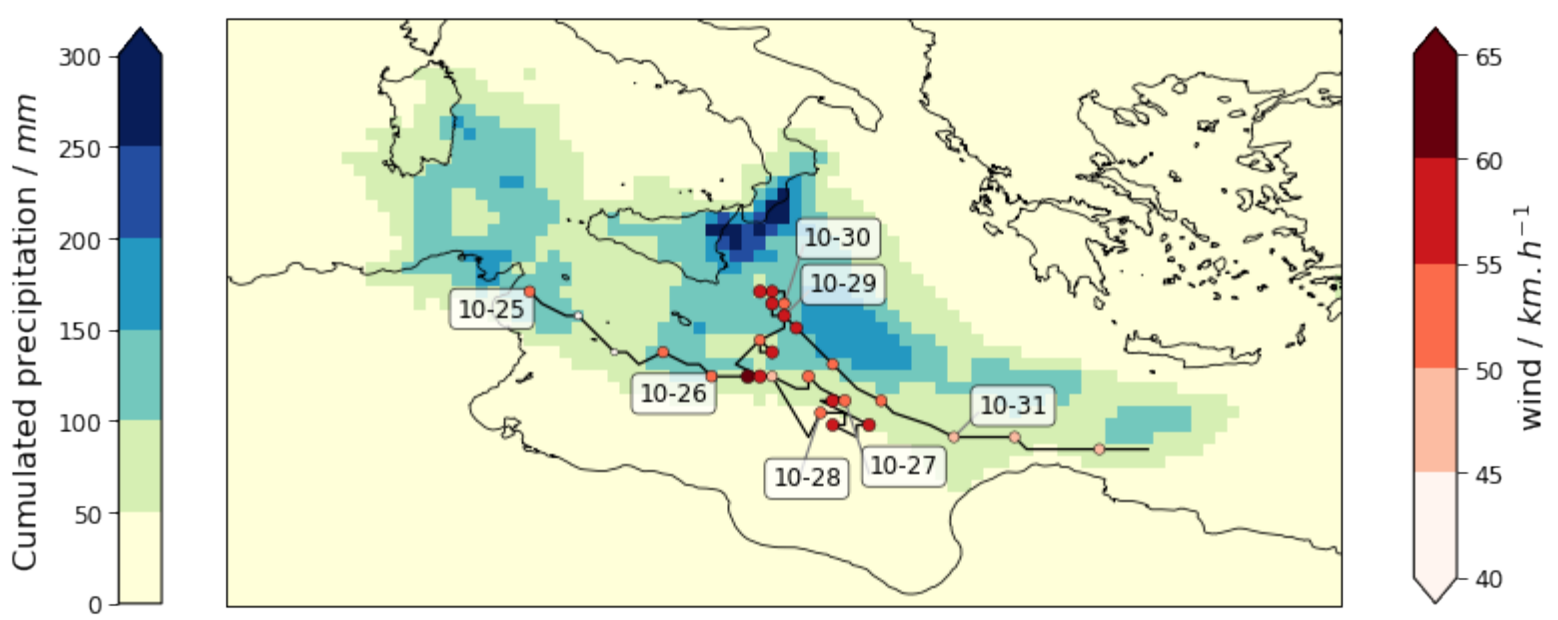

Figure 9. Track and associated precipitation for Apollo. Data from ERA5: Track position is retrieved as the local minimum of $s l p$, wind is the maximum wind speed in a $1.5^{\circ}$ GCD radius of the slp center, cumulated precipitation between 24-10-2021 and 31-10-2021. Time stamps are UTC, format mm-dd.

weakened on 30th October 2021 landfalling near Bayda and stayed inland until emerging over the Mediterranean a few hours later. Then, on 2nd of November, it dissipated off the coast of Turkey.

\subsubsection{Medicanes and climate change}

It is difficult to study the modification of frequency and intensity of medicanes in climate change. First of all, our knowledge of historical medicanes is very limited before the satellite era: their frequency is estimated between 1 and 2 events per year (Cavicchia et al., 2014a). Medicanes genesis is favored when an extratropical depression gets isolated from the polar jet stream. This "cut off" becomes quasi-stationary on the Mediterranean sea and can use the large availability of heat and humidity from the sea to produce organized convection. Recent studies of medicanes in climate change have therefore considered two elements: the precursors, namely the cut-off low that get isolated from the jet stream in the Mediterranean sea and the potential for organized convection once the first condition is met (Cavicchia et al., 2014b; Romero and Emanuel, 2017; Tous et al., 2016). On one hand, there is a general consensus that the jet stream will shift northward and therefore cut-off low will become slightly less probable on the Mediterranean sea. On the other hand, the Mediterranean sea is warming faster than oceans, increasing the potential for convection once a depression system is present in the area. We then expect to see less medicanes but more intense ones (González-Alemán et al., 2019).

\subsubsection{Attribution of Medicane Apollo to climate change}

465 We now use the ERA5 dataset to perform the attribution of the cyclonic circulation associated with Apollo in the past and present climate. First of all, let us note that we will select analogs independently on the extratropical or tropical nature of the 
depression that have produced them. Figure 10 shows the results for Apollo. We already observe that the analogs average $s l p$ for both the periods (b,c) do not reach slp minima comparable to that of Apollo (a) hinting to the uniqueness of this event. The $\Delta s l p$ (d) do not display any interesting structure. Instead, we observe that temperatures (e-g) are significantly warmer (h) the factual world especially on the island of Sicily and on the southern Mediterranean basin. This warming is associated with a significant increase of precipitation in the factual period due to the larger availability of heat and humidity from the sea (i-1). These results must be taken with care because the analogs quality $Q>60 \mathrm{hPa}(\mathrm{m})$ clearly shows that this circulation pattern is rarer compared with the rest of its analogs. As in the case of Storm Filomena, Apollo appears to be a black swan event. We do not detect remarkable changes in the predictability index D (n) but we see a slightly increase in the persistence $\Theta$ (o) which could also have contributed to enhance the persistence of precipitation on the same areas. Finally we do see an increase of analogs in the month of September in the factual period (p): this is the warmest month for the Mediterranean sea, hence the most favorable for the development of deep convection in association with cyclonic depressions. This factor can greatly enhance precipitations, especially on the mountain ranges exposed to the winds, as in the case of Apollo, for the Etna and the Peloritani mountain ranges.

With respect to the general statements reported in Section 4.7.1, our analysis also highlights the potential intensification of precipitation associated with cyclones around the island of Sicily, supported both by higher temperatures and increased occurrence of cyclones in the month of September, the warmest for the Mediterranean sea. However, we point to the black swan nature of this storm compared to its analogs, and therefore to a careful interpretation of the attribution results obtained above.

\subsection{Scandinavian cold spell}

During late November 2021, Scandinavia experienced record-low temperatures for the season. On the 28th November, Nikkaluokta weather station in Sweden recorded $-37,4{ }^{\circ} \mathrm{C}$, which was the lowest November temperature recorded in the country since 1980. Other stations in northern Sweden recorded their lowest November temperatures since the 1950s (SMHI, a). Comparable records occurred in the first days of December. In Norway, the $-36,7^{\circ} \mathrm{C}$ recorded in Kautokeino was the lowest November reading since 2002 (SMHI, b). These frigid temperatures were part of a broader area of below-average temperatures, peaking in the last week of November and first days of December, and stretching from North-Western Russia all the way to Spain (which recorded one of the top 10 coldest November months on record (AEMET)). The cold spell impacted transports, including suspension of entire train lines (SVT) and an unusually large number of road accidents in southern Sweden (SVD).

The cold spell was associated with a large ridge forming over the North Atlantic starting from the 23rd November, and drawing cold Arctic and Siberian air over the continent. A pressure dipole with a high over Scandinavia and a low over central Europe further favoured cold air advection. The Atlantic ridge persisted until early December, after which a more zonal circulation occurred, bringing warmer airmasses over large parts of Europe. 

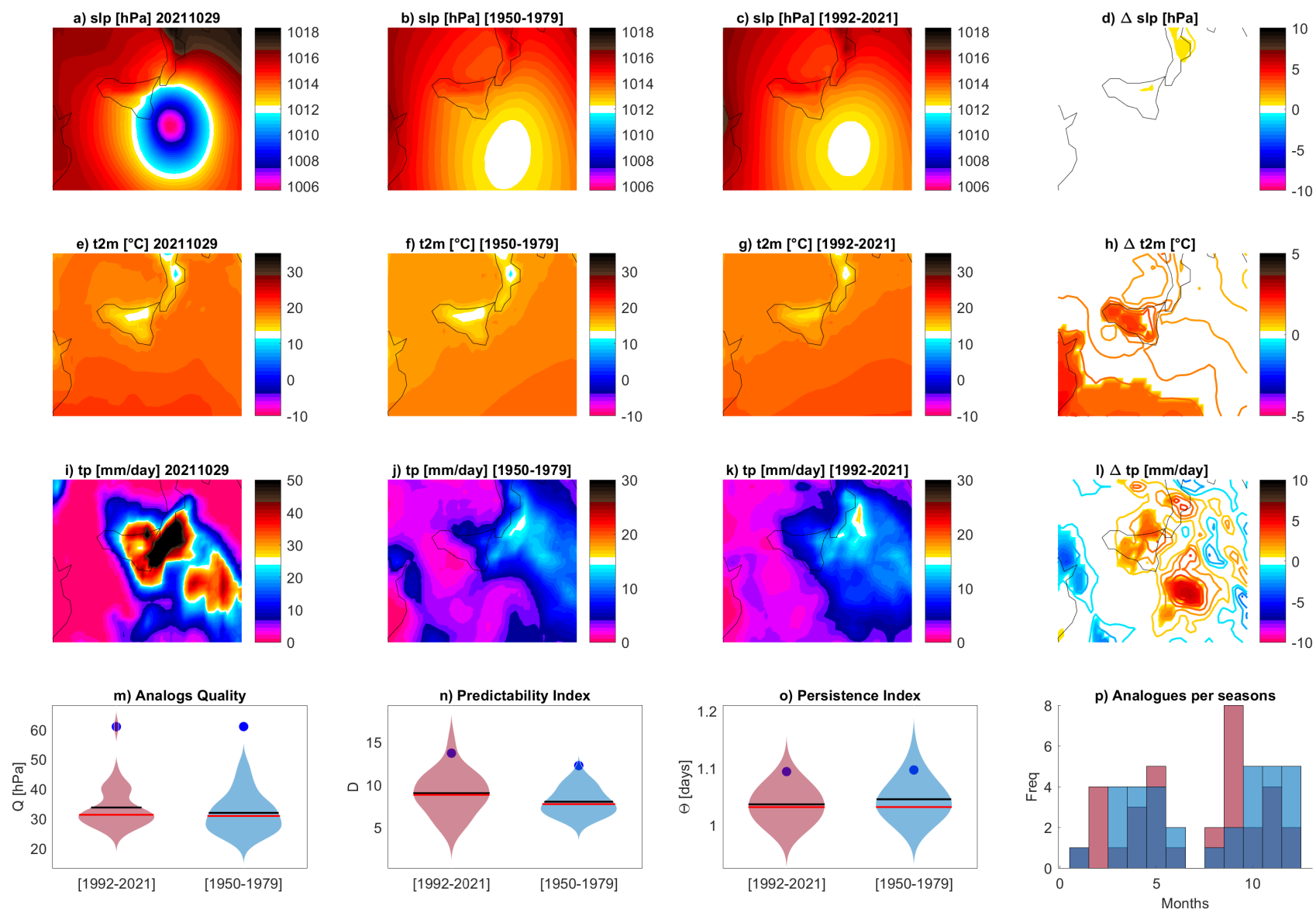

Figure 10. Attribution for the Medicane Apollo on 29-10-2021. Daily mean sea-level pressure $s l p$ (a), 2-meter temperatures $t 2 m$ (e) and total precipitation $t p$ (i) on the day of the event. Average of the 33 sea-level pressure analogs found for the counterfactual [1950-1979] (b) and factual [1992-2021] (c) periods and corresponding 2-meter temperatures (f,g) and daily precipitation rate (j,k). $\Delta s l p(\mathrm{~d}), \Delta t 2 m(\mathrm{~h})$ and $\Delta t p$ (i) between factual and counterfactual periods: colored-filled areas show significant anomalies with respect to the bootstrap procedure. Violin plots for counterfactual (blue) and factual (pink) periods for the Analogs Quality $Q(\mathrm{~m})$ the Predictability index $D$ (n), the Persistence index $\Theta(\mathrm{o})$ and the distribution of analogs in each month (p). Values for the selected day are marked by a blue dot.

\subsubsection{Scandinavian Cold Spells and Climate Change}

As discussed in Sect. 4.2.1, it is virtually certain that there has been a decrease in severity and/or frequency of cold spells in the last several decades, and the consensus is that at a global level this decrease will continue in the future. Scandinavia fits this trend, and has shown a significant decrease in wintertime cold spell days in recent decades (Matthes et al., 2015). In the future, the decrease in wintertime cold days is expected to be stronger than in several other European regions (Dosio, 2016), as is the 
increase in yearly minimum daily-mean temperature (Bernes, 2017, p. 102).

\section{Conclusions}

We have analyzed the atmospheric circulation associated with a selection of high-impact extreme events occurring in 2021 from an attribution perspective. Specifically, we have performed a semi-objective selection of a representative day for each extreme, and have then identified two sets of analogs. The first in the 1950-1979 period, which approximates a counterfactual world; the second in the 1992-2021 period, which approximates a factual world. Regardless the specificity of each event, our analysis allows us to draw some conclusions that may be of relevance to the broader field of extreme event attribution. First, many circulation patterns leading to extremes occur preferentially during a specific season, but are observed with lower frequency during all seasons (e.g. see the attribution of Filomena winter storm or the French spring cold spell). For many events, we have been able to identify seasonal shifts in the occurrence of event analogs with major implications for their surface impacts (e.g. 

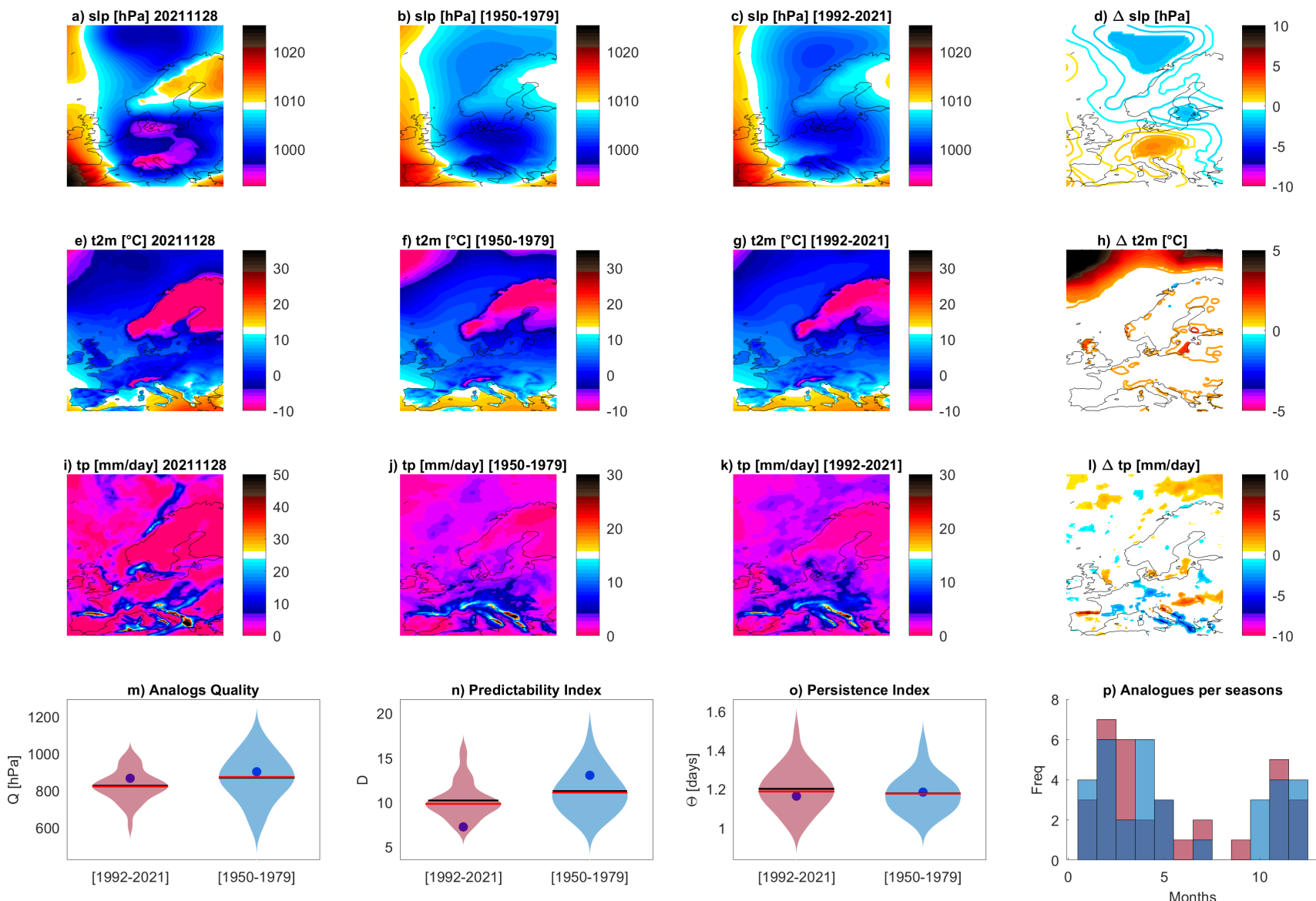

Figure 11. Attribution for the Scandinavian Cold Spell on 28-11-2021. Daily mean sea-level pressure $s l p$ (a), 2-meter temperatures $t 2 m$ (e) and total precipitation $t p$ (i) on the day of the event. Average of the 33 sea-level pressure analogs found for the counterfactual [1950-1979] (b) and factual [1992-2021] (c) periods and corresponding 2-meter temperatures (f,g) and daily precipitation rate (j,k). $\Delta s l p(\mathrm{~d}), \Delta t 2 m(\mathrm{~h})$ and $\Delta t p$ (i) between factual and counterfactual periods: colored-filled areas show significant anomalies with respect to the bootstrap procedure. Violin plots for counterfactual (blue) and factual (pink) periods for the Analogs Quality $Q(\mathrm{~m})$ the Predictability index $D$ (n), the Persistence index $\Theta(\mathrm{o})$ and the distribution of analogs in each month (p). Values for the selected day are marked by a blue dot.

see the attribution of the Scandinavian cold spell). This can occur independently of large changes in the analogue circulation patterns or the thermodynamic effect of global mean surface warming.

A second important outcome of this study is to include, in the attribution framework, the systematic use of the dynamical indicators of persistence and predictability. Persistence is of particular interest, since there has been a lively scientific debate on changes in atmospheric persistence and how this may affect extreme events (Coumou and Rahmstorf, 2012; Hoskins and Woollings, 2015; Wehrli et al., 2020). 
Finally, we have studied the quality of the analogs, the "typicality" of the analogs relative to the atmospheric variability and their changes over time. This brings a third relevant outcome, namely the ability to understand whether both a given circulation and its analogs are becoming more or less "typical" (i.e. have better or worse analogs). The two do not always vary in tandem, meaning that the quality of the analogs for a given extreme may remain unchanged while the analogs of the analogs become better. While not immediate to interpret, this provides some subtle insights into how the configurations conducive to an extreme relate to the broader atmospheric variability typical of a given climate. In the case of the storm Filomena and the medicane Apollo, the lack of analogs of good quality directly points to the emergence of this event as an unprecedented one, a black swan among the weather patterns in Europe. This warns that weather extreme events can appear without belonging to an existing population. It is therefore questionable to attempt any attribution statements in this case.

The main limitations of our framework include the somewhat arbitrary choices of the region used to define the analogs, the time scale for the selection of the analogs and of the number of analogs. We are well aware of these limitations, and have designed the study to minimise their impact. The main advantage of working with analogs of sea-level pressure is the possibility of applying expert judgement to select a region that includes the large-scale cyclonic/anticyclonic structures concurring with the event. The use of daily averages allows to average out the daily cycle. Longer time scales have been tested but they produce worse analogs due to the fact that the synoptic structures move too much and lead to aliased atmospheric patterns. Furthermore, information about the eventual stationarity of the patterns is retained in the persistence metrics. Finally we have tested the dependence on the number of analogs used and found that an optimum performance is reached between 30 and 60 analogs, i.e. a number sufficiently high to have a meaningful statistics but low enough to have authentic analogs. A metric of quality of analogs has been added to control the outcome of the analogs search. Finally we highlight that conventional extreme value attribution shares many of the same limitations, including the choice of the region, thresholds and time scale.

Our approach does not want to substitute extreme value attributions based on the statistical fitting of extreme value distributions: those approaches can be used to provide an immediate answers to stakeholders in changes of return times of extreme events in factual versus counterfactual worlds and have been successfully used by the attribution community in a large number of instances (Trenberth et al., 2015; Van Oldenborgh and Van Ulden, 2003; Vautard and Yiou, 2012; Van Oldenborgh et al., 2012; Trenberth et al., 2015; Vautard et al., 2016, 2018). We rather see our analysis as complementing statistical approaches by providing insights on the possible changes over time of the dynamics underlying an extreme events from a dynamical perspective. Further development of this methodology can include the use of analogs to flag population of events that share the same dynamical origin, on the line of research proposed by Jézéquel et al. (2018b) and Shepherd (2019). This would allow to perform an attribution conditioned to the analogs and the release of an automated package that produces these analyses in matter of minutes as soon as the ERA5 data are available. Other possible extensions include searching for analogs of different observables such as geopotential height, temperature on pressure levels, winds and more. Although valuable, these options must be evaluated with extreme care in the context of attribution because of the non-linear trends already introduced by the anthropogenic forcing on the average of these quantities (Jézéquel et al., 2018a).

To conclude, the analogs approach to extreme event attribution shows that many extreme events are significantly modified in present climate with respect to the past, because of changes in the position, persistence and seasonality of cyclonic/anticyclonic 
patterns. Our approach, complementary to the statistical methods already available in the attribution community, underscore the importance of considering changes in the atmospheric circulation when performing attribution studies.

Code availability. The code to compute the dynamical indicators of predictability $D$ and persistence $\theta$ is available at https://fr.mathworks.c om/matlabcentral/fileexchange/95768-attractor-local-dimension-and-local-persistence-computation

Data availability. ERA5 is the latest climate reanalysis being produced by ECMWF as part of implementing the EU- funded Copernicus Climate Change Service (C3S), providing hourly data on atmospheric, land-surface and sea-state parameters together with estimates of uncertainty from 1979 to present day. ERA5 data are available on the C3S Climate Data Store on regular latitude-longitude grids at $0.25^{\circ} \mathrm{x}$ $0.25^{\circ}$ resolution at https://cds.climate.copernicus.eu/\#!/home, accessed on 2022-01-26

\section{Appendix A: Predictability and Persistence Indices}

The attractor of a dynamical system is a geometric object defined in the space hosting all the possible states of the system (phase-space). Each point $\zeta$ on the attractor can be characterized by two dynamical indicators: the local dimension $D$, which indicates the number of degrees of freedom active locally around $\zeta$, and the persistence $\Theta$, a measure of the mean residence time of the system around $\zeta$ (Faranda et al., 2017a). To determine $D$, we exploit recent results from the application of extreme value theory to Poincaré recurrences in dynamical systems. This approach considers long trajectories of a system — in our case successions of daily SLP latitude-longitude maps - corresponding to a sequence of states on the attractor. For a given point $\zeta$ in phase space (e.g., a given SLP map), we compute the probability that the system returns within a ball of radius $\epsilon$ centered on the point $\zeta$. The Freitas et al. (2010) theorem, modified by Lucarini et al. (2012), states that logarithmic returns:

$g(x(t))=-\log (\operatorname{dist}(x(t), \zeta))$

yield a probability distribution such that:

$\operatorname{Pr}(z>s(q)) \simeq \exp \left[-\vartheta(\zeta)\left(\frac{z-\mu(\zeta)}{\sigma(\zeta)}\right)\right]$

where $z=g(x(t))$ and $s$ is a high threshold associated to a quantile $q$ of the series $g(x(t))$. Requiring that the orbit falls within a ball of radius $\epsilon$ around the point $\zeta$ is equivalent to asking that the series $g(x(t))$ is over the threshold $s$; therefore, the ball radius $\epsilon$ is simply $e^{-s(q)}$. The resulting distribution is the exponential member of the Generalized Pareto Distribution family. The parameters $\mu$ and $\sigma$, namely the location and the scale parameter of the distribution, depend on the point $\zeta$ in phase space. $\mu(\zeta)$ corresponds to the threshold $s(q)$ while the local dimension $d(\zeta)$ can be obtained via the relation $\sigma=1 / D(\zeta)$. This is the metric of predictability introduced in Sect. 3. 
When $x(t)$ contains all the variables of the system, the estimation of $D$ based on extreme value theory has a number of advantages over traditional methods (e.g. the box counting algorithm (Liebovitch and Toth, 1989; Sarkar and Chaudhuri, 1994)). First, it does not require to estimate the volume of different sets in scale-space: the selection of $s(q)$ based on the quantile provides a selection of different scales $s$ which depends on the recurrence rate around the point $\zeta$. Moreover, it does not require the a priori selection of the maximum embedding dimension as the observable $g$ is always a univariate time-series.

The persistence of the state $\zeta$ is measured via the extremal index $0<\vartheta(\zeta)<1$, an adimensional parameter, from which we extract $\Theta(\zeta)=\Delta t / \vartheta(\zeta)$. $\Theta(\zeta)$ is therefore the average residence time of trajectories around $\zeta$, namely the metric of persistence introduced in Sect. 3, and it has unit of a time (in this study days). If $\zeta$ is a fixed point of the attractor $\Theta(\zeta)=\infty$. For a trajectory that leaves the neighborhood of $\zeta$ at the next time iteration, $\Theta=1$. To estimate $\vartheta$, we adopt the Süveges estimator (Süveges,

610 2007). For further details on the the extremal index, see Lucarini et al. (2016a).

Author contributions. D Faranda conceived the study and performed the attribution analysis for each event, he wrote the section on the medicane Apollo. S Bourdin wrote the section on Hurricane Ida and performed cyclones tracking. M Ginesta wrote the section about storm Filomena. M Krouma wrote the section about the Mediterranean Heatwave. G Messori wrote the section about the Scandinavian Cold Spell. R Noyelle wrote the section about the Westphalia floods. Flavio Pons wrote the section about Tornadoes outbreak. Pascal Yiou wrote the 615 section about the French spring cold-spell. All the authors contributed writing and reviewing the introduction, methods and conclusion of the article.

Competing interests. The authors declare no competing interests

Acknowledgements. The author wishes to thank MC Alvarez-Castro, J Riboldi, M Galfi, M Vrac, A Hisi, E Coppola and R Vautard for the discussions. The authors acknowledge the support of the INSU-CNRS-LEFE-MANU grant (project DINCLIC), as well as the gran ANR19-ERC7-0003 (BOREAS). This work has received support from the European Union's Horizon 2020 research and innovation programme under grant agreement No. 101003469 (XAIDA), by the European Research Council (ERC) grant agreement No. 948309 (CENÆ), and the Marie Sklodowska-Curie grant agreement No. 956396 (EDIPI). 


\section{References}

3Bmeteo: Caldo Storico in Sicilia, https://www.3bmeteo.com/giornale-meteo/cronaca-meteo---caldo-storico-in-sicilia--raggiunti-i-49-c---il-nuovo-record-europeo-504610, accessed: 2022-01-31, 2021.

AEMET: Spanish State Meteorological Agency: Noviembre de 2021, un mes muy frío, https://www.aemet.es/es/noticias/2021/12/resumen _clima_noviembre_2021, accessed: 2022-01-14.

AEMET: Spanish State Meteorological Agency, https://aemetblog.es/2021/08/18/la-ola-de-calor-del-puente-de-agosto21-y-los-records-d e-temperaturas-en-espana/, accessed: 2022-01-27, 2021a.

AEMET: Spanish State Meteorological Agency: Informe sobre la borrasca Filomena y la ola de frio, http://www.aemet.es/documentos/es/c onocermas/recursos_en_linea/publicaciones_y_estudios/estudios/Informe_episodio_filomena.pdf, accessed: 2021, 2021b.

Alberoni, P., Nanni, S., Crespi, M., and Monai, M.: The supercell thunderstorm on 8 June 1990: mesoscale analysis and radar observations, Meteorology and Atmospheric Physics, 58, 123-138, 1996.

Allan, R. P., Hawkins, E., Bellouin, N., and Collins, B.: IPCC, 2021: Summary for Policymakers, 2021.

Antonescu, B., Schultz, D. M., Holzer, A., and Groenemeijer, P.: Tornadoes in Europe: An underestimated threat, Bulletin of the American Meteorological Society, 98, 713-728, 2017.

Aon: Global Catastrophe Recap, http://thoughtleadership.aon.com/documents/20210209_analytics-if-january-global-recap.pdf, accessed: January 2021, 2021.

Baker, A. J., Hodges, K. I., Schiemann, R. K., and Vidale, P. L.: Historical variability and lifecycles of North Atlantic midlatitude cyclones originating in the tropics, Journal of Geophysical Research: Atmospheres, 126, e2020JD033 924, 2021.

Bala, G., Caldeira, K., and Nemani, R.: Fast versus slow response in climate change: implications for the global hydrological cycle, Climate dynamics, 35, 423-434, 2010.

BBC: Polar vortex death toll rises to 21 as US cold snap continues, https://www.bbc.com/news/world-us-canada-47088684, accessed: 2022-01-14.

645 Bernes, C.: En varmare värld: Växthuseffekten och klimatets förändringar-Tredje upplagan, 2017.

Blackport, R. and Screen, J. A.: Weakened evidence for mid-latitude impacts of Arctic warming, Nature Climate Change, 10, 1065-1066, 2020.

Brooks, H. E., Carbin, G. W., and Marsh, P. T.: Increased variability of tornado occurrence in the United States, Science, 346, 349-352, 2014.

Casson, N., Contosta, A., Burakowski, E., Campbell, J., Crandall, M., Creed, I., Eimers, M., Garlick, S., Lutz, D., Morison, M., et al.: Winter

650 weather whiplash: Impacts of meteorological events misaligned with natural and human Systems in Seasonally Snow-Covered Regions, Earth's Future, 7, 1434-1450, 2019.

Cavicchia, L., von Storch, H., and Gualdi, S.: A long-term climatology of medicanes, Climate dynamics, 43, 1183-1195, 2014a.

Cavicchia, L., von Storch, H., and Gualdi, S.: Mediterranean tropical-like cyclones in present and future climate, Journal of Climate, 27 , 7493-7501, 2014b.

655 CDC: Deaths Related to Hurricane Ida, https://www.cdc.gov/mmwr/volumes/70/wr/mm7039a3.htm, accessed: 2022-01-31, 2021.

CEMS: COPERNICUS Emergency Management Service, https://emergency.copernicus.eu/mapping/list-of-components/EMSR538, accessed: 2022-01-31, 2021a.

CEMS: COPERNICUS Emergency Management Service, https://emergency.copernicus.eu/mapping/list-of-components/EMSR541, accessed: 2022-01-31, 2021b. 

ent-service-monitors-fire-events-mediterranean-region, accessed: 2022-01-31, 2021c.

CNN: These US cities had the coldest morning in decades - with some reaching all-time record lows, https://edition.cnn.com/2021/02/16/u s/record-cold-weather-us-trnd/index.html, accessed: 2022-01-14.

Cohen, J., Jones, J., Furtado, J. C., and Tziperman, E.: Warm Arctic, cold continents: A common pattern related to Arctic sea ice melt, snow advance, and extreme winter weather, Oceanography, 26, 150-160, 2013.

Cohen, J., Zhang, X., Francis, J., Jung, T., Kwok, R., Overland, J., Tayler, P. C., Lee, S., Laliberte, F., and Feldstein, S.: Arctic change and possible influence on mid-latitude climate and weather: a US CLIVAR White Paper, US CLIVAR, 2018.

Coumou, D. and Rahmstorf, S.: A decade of weather extremes, Nature climate change, 2, 491-496, 2012.

D'errico, M., Yiou, P., Nardini, C., Lunkeit, F., and Faranda, D.: Warmer Mediterranean temperatures do not decrease snowy cold spell intensity over Italy, https://hal.archives-ouvertes.fr/hal-02367559/document, 2019.

DieWelt: "Hochwasser aktuell: Zahl der Toten in Rheinland-Pfalz steigt auf 135 - Mindestens 184 Opfer durch Flut in Deutschland", https: //www.welt.de/vermischtes/live232509543/Hochwasser-aktuell-Mindestens-177-Opfer-durch-Flut-in-Deutschland.html, accessed: 2021-07-22, 2021.

Dosio, A.: Projections of climate change indices of temperature and precipitation from an ensemble of bias-adjusted high-resolution EUROCORDEX regional climate models, Journal of Geophysical Research: Atmospheres, 121, 5488-5511, 2016.

Doss-Gollin, J., Farnham, D. J., Lall, U., and Modi, V.: How unprecedented was the February 2021 Texas cold snap?, Environmental Research Letters, 16, 064 056, 2021.

Doswell III, C. A., Brooks, H. E., and Dotzek, N.: On the implementation of the enhanced Fujita scale in the USA, Atmospheric Research, 93, 554-563, 2009.

680 Elsner, J. B., Elsner, S. C., and Jagger, T. H.: The increasing efficiency of tornado days in the United States, Climate Dynamics, 45, 651-659, 2015.

Elsner, J. B., Fricker, T., and Schroder, Z.: Increasingly powerful tornadoes in the United States, Geophysical Research Letters, 46, 392-398, 2019.

Faranda, D.: An attempt to explain recent trends in European snowfall extremes, Weather Clim. Dynam. Discuss., 2019, 1-20, https://doi.org/10.5194/wcd-2019-15, 2019.

Faranda, D., Messori, G., and Yiou, P.: Dynamical proxies of North Atlantic predictability and extremes, Scientific reports, 7, 41 278, 2017 a.

Faranda, D., Messori, G., and Yiou, P.: Dynamical proxies of North Atlantic predictability and extremes, Scientific reports, 7, 41 278, https://www.nature.com/articles/srep41278.pdf, 2017b.

Faranda, D., Alvarez-Castro, M. C., Messori, G., Rodrigues, D., and Yiou, P.: The hammam effect or how a warm ocean enhances large scale atmospheric predictability, Nature communications, 10, 1-7, 2019a.

Faranda, D., Messori, G., and Vannitsem, S.: Attractor dimension of time-averaged climate observables: insights from a low-order oceanatmosphere model, Tellus A: Dynamic Meteorology and Oceanography, 71, 1-11, 2019b.

Faranda, D., Vrac, M., Yiou, P., Jézéquel, A., and Thao, S.: Changes in future synoptic circulation patterns: consequences for extreme event attribution, Geophys. Res. Lett., 47, e2020GL088 002, iSBN: 0094-8276 Publisher: Wiley Online Library, 2020.

Flannigan, M. D., Stocks, B. J., and Wotton, B. M.: Climate change and forest fires, Science of the total environment, 262, 221-229, 2000.

Freitas, A. C. M., Freitas, J. M., and Todd, M.: Hitting time statistics and extreme value theory, Probability Theory and Related Fields, 147, 675-710, 2010. 
Freitas, A. C. M., Freitas, J. M., and Todd, M.: Extreme value laws in dynamical systems for non-smooth observations, Journal of Statistical Physics, 142, 108-126, 2011.

Freitas, A. C. M., Freitas, J. M., and Vaienti, S.: Extreme Value Laws for sequences of intermittent maps, arXiv preprint arXiv:1605.06287, 2016.

González-Alemán, J. J., Pascale, S., Gutierrez-Fernandez, J., Murakami, H., Gaertner, M. A., and Vecchi, G. A.: Potential increase in hazard from Mediterranean hurricane activity with global warming, Geophysical Research Letters, 46, 1754-1764, 2019.

Gordon, L. J., Steffen, W., Jönsson, B. F., Folke, C., Falkenmark, M., and Johannessen, Å.: Human modification of global water vapor flows from the land surface, Proceedings of the National Academy of Sciences, 102, 7612-7617, 2005.

Haarsma, R.: European Windstorm Risk of Post-Tropical Cyclones and the Impact of Climate Change, Geophysical Research Letters, 48, e2020GL091 483, 2021.

Horton, R. M., Mankin, J. S., Lesk, C., Coffel, E., and Raymond, C.: A review of recent advances in research on extreme heat events, Current Climate Change Reports, 2, 242-259, 2016.

710 Hoskins, B. and Woollings, T.: Persistent extratropical regimes and climate extremes, Current Climate Change Reports, 1, 115-124, 2015.

HotNews.ro: "Een van de twee laatste vermiste personen na overstromingen in ons land teruggevonden", https://www.hln.be/binnenland/ee n-van-de-twee-laatste-vermiste-personen-na-overstromingen-in-ons-land-teruggevonden a4a4c681/, accessed: 2021-07-29, 2021.

$\mathrm{Hu}$, S., Zhang, W., Turner, A. G., and Sun, J.: How does El Niño-Southern Oscillation affect winter fog frequency over eastern China?, Climate Dynamics, 54, 1043-1056, 2020.

Insurance, B.: "Recent floods cause nearly \$12 billion damage in Belgium", https://www.businessinsurance.com/article/00010101/STORY 1912343432/Recent-floods-cause-nearly-Iprotect|T1\textdollar12-billion-damage-in-Belgium, accessed: 2022-01-27.

jbarisk: Hurricane-like storm causes flooding in the Mediterranean, October 2021, https://www.jbarisk.com/flood-services/event-response /medicane-apollo, accessed: 2022-02-01, 2021.

Jézéquel, A., Dépoues, V., Guillemot, H., Trolliet, M., Vanderlinden, J.-P., and Yiou, P.: Behind the veil of extreme event attribution, Climatic Change, 149, 367-383, 2018.

Jolly, E., D’Andrea, F., Rivière, G., and Fromang, S.: Linking warm Arctic winters, Rossby waves and Cold Spells: an idealized numerical study, Journal of the Atmospheric Sciences, 2021.

Junghänel, T., Bissolli, P., Daßler, J., Fleckenstein, R., Imbery, F., Janssen, W., Kaspar, F., Lengfeld, K., Leppelt, T., Rauthe, M., et al.: Hydro-klimatologische Einordnung der Stark-und Dauerniederschläge in Teilen Deutschlands im Zusammenhang mit dem Tiefdruckgebiet „Bernd “vom 12. bis 19. Juli 2021, Deutscher Wetterdienst, 2021.

Jézéquel, A., Cattiaux, J., Naveau, P., Radanovics, S., Ribes, A., Vautard, R., Vrac, M., and Yiou, P.: Trends of atmospheric circulation during singular hot days in Europe, Environmental Research Letters, 13, 054 007, https://iopscience.iop.org/article/10.1088/1748-9326/aab5da/ pdf, 2018a.

Jézéquel, A., Dépoues, V., Guillemot, H., Trolliet, M., Vanderlinden, J.-P., and Yiou, P.: Behind the veil of extreme event attribution, Climatic Change, https://doi.org/https://doi-org.insu.bib.cnrs.fr/10.1007/s10584-018-2252-9, 2018b.

Kautz, L.-A., Polichtchouk, I., Birner, T., Garny, H., and Pinto, J. G.: Enhanced extended-range predictability of the 2018 late-winter Eurasian cold spell due to the stratosphere, Quarterly Journal of the Royal Meteorological Society, 146, 1040-1055, 2020.

Knapp, K. R., Kruk, M. C., Levinson, D. H., Diamond, H. J., and Neumann, C. J.: The international best track archive for climate stewardship (IBTrACS) unifying tropical cyclone data, Bulletin of the American Meteorological Society, 91, 363-376, 2010. 
https://doi.org/10.5194/wcd-2022-9

Preprint. Discussion started: 17 February 2022

(c) Author(s) 2022. CC BY 4.0 License.

(c) (i)

Weather and

Climate Dynamics

Discussions

Knapp, Kenneth R et al.: International Best Track Archive for Climate Stewardship (IBTrACS) Project, Version 4., https://doi.org/10.25921 /82ty-9e16, accessed: 2022-01-26, 2018.

Knutson, T., Camargo, S. J., Chan, J. C., Emanuel, K., Ho, C.-H., Kossin, J., Mohapatra, M., Satoh, M., Sugi, M., Walsh, K., et al.: Tropical cyclones and climate change assessment: Part I: Detection and attribution, Bulletin of the American Meteorological Society, 100, 19872007, 2019.

740

Knutson, T., Camargo, S. J., Chan, J. C., Emanuel, K., Ho, C.-H., Kossin, J., Mohapatra, M., Satoh, M., Sugi, M., Walsh, K., et al.: Tropical cyclones and climate change assessment: Part II: Projected response to anthropogenic warming, Bulletin of the American Meteorological Society, 101, E303-E322, 2020.

Kodra, E., Steinhaeuser, K., and Ganguly, A. R.: Persisting cold extremes under 21st-century warming scenarios, Geophysical research letters, 38, 2011.

Kossin, J. P.: A global slowdown of tropical-cyclone translation speed, Nature, 558, 104-107, 2018.

Kossin, J. P., Emanuel, K. A., and Vecchi, G. A.: The poleward migration of the location of tropical cyclone maximum intensity, Nature, 509, 349-352, 2014.

Kral-O’Brien, K. C., O’Brien, P. L., and Harmon, J. P.: Need for false spring research in the Northern Great Plains, USA, Agricultural \& Environmental Letters, 4, 190 025, 2019.

Kreienkamp, F., Philip, S. Y., Tradowsky, J. S., Kew, S. F., Lorenz, P., Arrighi, J., Belleflamme, A., Bettmann, T., Caluwaerts, S., Chan, S. C., et al.: Rapid attribution of heavy rainfall events leading to the severe flooding in Western Europe during July $2021,2021$.

Kundzewicz, Z. W., Pińskwar, I., and Brakenridge, G. R.: Changes in river flood hazard in Europe: a review, Hydrology research, 49, 294$302,2018$.

Kundzewicz, Z. W., Szwed, M., and Pińskwar, I.: Climate variability and floods—A global review, Water, 11, $1399,2019$.

LaChaineMeteo: Bilan climatique d'avril 2021 : entre sécheresse et records de froid, https://actualite.lachainemeteo.com/actualite-meteo/20 21-05-05/bilan-climatique-d-avril-2021-entre-secheresse-et-records-de-froid-59270, accessed: 2022-02-01, 2021.

Lee, J.-Y., Marotzke, J., Bala, G., Cao, L., Corti, S., Dunne, J., Engelbrecht, F., Fischer, E., Fyfe, J., Jones, C., Maycock, A., Mutemi, J., Ndiaye, O., Panickal, S., , and Zhou, T.: Future Global Climate: Scenario-Based Projections and Near-Term Information. In Climate Change 2021: The Physical Science Basis. Contribution of Working Group I to the Sixth Assessment Report of the Intergovernmental Panel on Climate Change, 2021.

Lee, S. H. and Butler, A. H.: The 2018-2019 Arctic stratospheric polar vortex, Weather, 75, 52-57, 2020.

LeMonde: La vague de froid se poursuit en Europe et fait des dizaines de morts, https://www.lemonde.fr/climat/article/2018/02/28/la-vagu e-de-froid-se-poursuit-en-europe-et-fait-des-dizaines-de-morts_5263856_1652612.html, accessed: 2022-01-14, 2018.

Liebovitch, L. S. and Toth, T.: A fast algorithm to determine fractal dimensions by box counting, physics Letters A, 141, 386-390, 1989.

Lillo, S. P., Cavallo, S. M., Parsons, D. B., and Riedel, C.: The Role of a Tropopause Polar Vortex in the Generation of the January 2019 Extreme Arctic Outbreak, Journal of the Atmospheric Sciences, 78, 2801-2821, 2021.

Lucarini, V., Faranda, D., and Wouters, J.: Universal behaviour of extreme value statistics for selected observables of dynamical systems, Journal of statistical physics, 147, 63-73, 2012.

Lucarini, V., Faranda, D., de Freitas, J. M. M., Holland, M., Kuna, T., Nicol, M., Todd, M., Vaienti, S., et al.: Extremes and recurrence in dynamical systems, John Wiley \& Sons, 2016a.

Lucarini, V., Faranda, D., Freitas, A. C. M., Freitas, J. M., Holland, M., Kuna, T., Nicol, M., Todd, M., and Vaienti, S.: Extremes and recurrence in dynamical systems, John Wiley \& Sons, 2016 b. 
https://doi.org/10.5194/wcd-2022-9

Preprint. Discussion started: 17 February 2022

(c) Author(s) 2022. CC BY 4.0 License.

Weather and

Climate Dynamics

(c) (1)

Madsen, H., Lawrence, D., Lang, M., Martinkova, M., and Kjeldsen, T.: Review of trend analysis and climate change projections of extreme precipitation and floods in Europe, Journal of Hydrology, 519, 3634-3650, 2014.

Matthes, H., Rinke, A., and Dethloff, K.: Recent changes in Arctic temperature extremes: warm and cold spells during winter and summer, Environmental Research Letters, 10, $114020,2015$.

Messori, G., Caballero, R., and Faranda, D.: A dynamical systems approach to studying midlatitude weather extremes, Geophysical Research Letters, 44, 3346-3354, 2017.

Meteoweb: Medicane Apollo, Aeronautica: per la prima volta un consorzio di Paesi europei ha dato un nome ufficiale ad un evento meteorologico, https://www.meteoweb.eu/2021/10/medicane-apollo-per-la-prima-volta-un-nome-ufficiale/1734332/, accessed: 2022-01-27, 2021.

Michaelis, A. C. and Lackmann, G. M.: Climatological changes in the extratropical transition of tropical cyclones in high-resolution global simulations, Journal of Climate, 32, 8733-8753, 2019.

Michelangeli, P.-A., Vautard, R., and Legras, B.: Weather regimes: Recurrence and quasi stationarity, Journal of the atmospheric sciences, 52, 1237-1256, 1995.

Mitchell, D., Heaviside, C., Vardoulakis, S., Huntingford, C., Masato, G., Guillod, B. P., Frumhoff, P., Bowery, A., Wallom, D., and Allen, M.: Attributing human mortality during extreme heat waves to anthropogenic climate change, Environmental Research Letters, 11, 074006 , 2016.

Moloney, N. R., Faranda, D., and Sato, Y.: An overview of the extremal index, Chaos: An Interdisciplinary Journal of Nonlinear Science, 29, $022101,2019$.

Mori, M., Watanabe, M., Shiogama, H., Inoue, J., and Kimoto, M.: Robust Arctic sea-ice influence on the frequent Eurasian cold winters in past decades, Nature Geoscience, 7, 869-873, 2014.

Naveau, P., Hannart, A., and Ribes, A.: Statistical methods for extreme event attribution in climate science, Annual Review of Statistics and its Application, 7, 89-110, 2020.

NCDC/NOAA: Billion-Dollar Weather and Climate Disasters, https://www.ncdc.noaa.gov/billions/events/US/2021, accessed: 2022-01-31, 2021.

NCEP/CPC: PSL Data: CPC Unified Gauge-Based Analysis of Daily Precipitation over CONUS RT: NOAA Physical Sciences Laboratory, https://psl.noaa.gov/data/gridded/data.unified.daily.conus.rt.html, accessed: 25-01-2022.

NHC/NOAA: National Hurricane Center - Hurricane KATRINA Advisory Archive, https://www.nhc.noaa.gov/archive/2005/KATRINA.sh tml, accessed: 2022-01-31, 2005.

NHC/NOAA: Costliest U.S. tropical cyclones tables updated, https://www.nhc.noaa.gov/news/UpdatedCostliest.pdf, accessed: 2022-01-31, 2018.

NHC/NOAA: National Hurricane Center - Hurricane IDA Advisory Archive, https://www.nhc.noaa.gov/archive/2021/IDA.shtml, accessed: 2022-01-31, 2021.

805 Ogawa, F., Keenlyside, N., Gao, Y., Koenigk, T., Yang, S., Suo, L., Wang, T., Gastineau, G., Nakamura, T., Cheung, H. N., et al.: Evaluating impacts of recent Arctic sea ice loss on the northern hemisphere winter climate change, Geophysical Research Letters, 45, 3255-3263, 2018.

Pendergrass, A. G., Knutti, R., Lehner, F., Deser, C., and Sanderson, B. M.: Precipitation variability increases in a warmer climate, Scientific reports, 7, 1-9, 2017. 

Struttura Idro-Meteo-Clima. Available online at: https://allertameteo.regione.emilia-romagna.it/documents/20181/437770/Evento+1920+settembre+2021.pdf/ff3ed88f-773d-06e9-eb02-d0a306ae9121?t=1633503536867 (Accessed January 26, 2022), 2022.

Román-Palacios, C. and Wiens, J. J.: Recent responses to climate change reveal the drivers of species extinction and survival, Proceedings of the National Academy of Sciences, 117, 4211-4217, 2020.

Romero, R. and Emanuel, K.: Climate change and Hurricane-like extratropical cyclones: Projections for North Atlantic polar lows and medicanes based on CMIP5 models, Journal of Climate, 30, 279-299, 2017.

Russo, S. and Sterl, A.: Global changes in indices describing moderate temperature extremes from the daily output of a climate model, Journal of Geophysical Research: Atmospheres, 116, 2011.

Sachweh, M. and Koepke, P.: Radiation fog and urban climate, Geophysical Research Letters, 22, 1073-1076, 1995.

Sainsbury, E. M., Schiemann, R. K., Hodges, K. I., Shaffrey, L. C., Baker, A. J., and Bhatia, K. T.: How important are post-tropical cyclones for European windstorm risk?, Geophysical Research Letters, 47, e2020GL089 853, 2020.

Sarkar, N. and Chaudhuri, B. B.: An efficient differential box-counting approach to compute fractal dimension of image, IEEE Transactions on systems, man, and cybernetics, 24, 115-120, 1994.

Scher, S. and Messori, G.: How global warming changes the difficulty of synoptic weather forecasting, Geophysical Research Letters, 46, 2931-2939, 2019.

Seneviratne, S., Zhang, X., Adnan, M., Badi, W., Dereczynski, C., Luca, A. D., Ghosh, S., Iskandar, I., Kossin, J., Lewis, S., Otto, F., Pinto, I., Satoh, M., Vicente-Serrano, S., Wehner, M., , and Zhou, B.: Weather and Climate Extreme Events in a Changing Climate. In Climate Change 2021: The Physical Science Basis. Contribution of Working Group I to the Sixth Assessment Report of the Intergovernmental Panel on Climate Change, 2021.

830 Shepherd, T. G.: Atmospheric circulation as a source of uncertainty in climate change projections, Nature Geoscience, 7, 703, 2014.

Shepherd, T. G.: A Common Framework for Approaches to Extreme Event Attribution, Current Climate Change Reports, 2, 28-38, https://doi.org/10.1007/s40641-016-0033-y, 2016.

Shepherd, T. G.: Storyline approach to the construction of regional climate change information, Proceedings of the Royal Society A, 475 , $20190013,2019$.

SIAS: Servizio Informativo Agrometeorologico Siciliano, http://www.sias.regione.sicilia.it/frameset_dati.htm, accessed: 2022-01-27, 2021.

SMHI: November 2021 - Nästan rekordkall avslutning, https://www.smhi.se/klimat/klimatet-da-och-nu/manadens-vader-och-vatten-sverig e/manadens-vader-i-sverige/november-2021-nastan-rekordkall-avslutning-1.176606, accessed: 2022-01-14, a.

SMHI: November 2021 - La Niña bidrog till översvämningar i sydvästra Kanada, https://www.smhi.se/klimat/klimatet-da-och-nu/manade ns-vader-i-varlden/november-2021-la-nina-bidrog-till-oversvamningar-i-sydvastra-kanada-1.176603, accessed: 2022-01-14, b.

840 Stefanon, M., D’Andrea, F., and Drobinski, P.: Heatwave classification over Europe and the Mediterranean region, Environmental Research Letters, 7, 014023, 2012.

Stendel, M., Francis, J., White, R., Williams, P. D., and Woollings, T.: The jet stream and climate change, in: Climate Change, pp. 327-357, Elsevier, 2021.

Süveges, M.: Likelihood estimation of the extremal index, Extremes, 10, 41-55, 2007.

845 SVD: Oväder drar österut - flera trafikolyckor, https://www.svd.se/fortsatta-snoproblem-i-soder, accessed: 2022-01-14.

SVT: Tågtrafik i Norrbotten ställs in - för kallt att köra, https://www.svt.se/nyheter/lokalt/norrbotten/tagtrafik-i-norrbotten-stalls-in-for-ka llt-att-kora, accessed: 2022-01-14 
https://doi.org/10.5194/wcd-2022-9

Preprint. Discussion started: 17 February 2022

(c) Author(s) 2022. CC BY 4.0 License.

(c) (i)

Weather and

Climate Dynamics

Discussions

Taleb, N.: The black swan: Why don't we learn that we don't learn, NY: Random House, 2005.

Tamarin-Brodsky, T., Hodges, K., Hoskins, B. J., and Shepherd, T. G.: A Dynamical Perspective on Atmospheric Temperature Variability and Its Response to Climate Change, Journal of Climate, 32, 1707-1724, 2019.

Tous, M., Zappa, G., Romero, R., Shaffrey, L., and Vidale, P. L.: Projected changes in medicanes in the HadGEM3 N512 high-resolution global climate model, Climate Dynamics, 47, 1913-1924, 2016.

Trenberth, K. E., Fasullo, J. T., and Shepherd, T. G.: Attribution of climate extreme events, Nature Clim. Change, 5, 725-730, http://dx.doi .org/10.1038/nclimate2657, 2015.

Trisos, C. H., Merow, C., and Pigot, A. L.: The projected timing of abrupt ecological disruption from climate change, Nature, 580, 496-501, 2020.

Ulbrich, U., Leckebusch, G. C., and Pinto, J. G.: Extra-tropical cyclones in the present and future climate: a review, Theoretical and Applied Climatology volume, 96, 117-131, 2009.

Van Oldenborgh, G. J. and Van Ulden, A.: On the relationship between global warming, local warming in the Netherlands and changes in circulation in the 20th century, International Journal of Climatology, 23, 1711-1724, <GotoISI >://000186918700003, 2003.

Van Oldenborgh, G. J., Van Urk, A., and Allen, M.: The absence of a role of climate change in the 2011 Thailand floods, Bull. Amer. Meteor. Soc, 93, 1047-1049, 2012.

van Oldenborgh, G. J., van der Wiel, K., Kew, S., Philip, S., Otto, F., Vautard, R., King, A., Lott, F., Arrighi, J., Singh, R., et al.: Pathways and pitfalls in extreme event attribution, Climatic Change, 166, 1-27, 2021.

Vautard, R. and Yiou, P.: ATTRIBUTION Robustness of warming attribution, Nature Climate Change, 2, 26-27, <GotoISI>://0002994955 00014, 2012.

Vautard, R., Yiou, P., Otto, F., Stott, P., Christidis, N., Oldenborgh, G. J. v., and Schaller, N.: Attribution of human-induced dynamical and thermodynamical contributions in extreme weather events, Environmental Research Letters, 11, 114 009, http://stacks.iop.org/1748-9326 $/ 11 / \mathrm{i}=11 / \mathrm{a}=114009,2016$.

Vautard, R., Colette, A., Van Meijgaard, E., Meleux, F., Jan van Oldenborgh, G., Otto, F., Tobin, I., and Yiou, P.: Attribution of Wintertime Anticyclonic Stagnation Contributing to Air Pollution in Western Europe, Bulletin of the American Meteorological Society, 99, S70-S75, 2018.

Vautard, R., van Oldenborg, G., Bonnet, R., Li, S., Robin, Y., Kew, S., Philip, S., Soubeyroux, J., Dubuisson, B., N, V., RIechstein, M., and Otto, F.: Human influence on growing period frosts like the early april 2021 in Central France, https://www.worldweatherattribution.org/ wp-content/uploads/GrowingPeriodFrost2021.pdf, accessed: 2022-01-31, 2021.

Wehrli, K., Hauser, M., and Seneviratne, S. I.: Storylines of the 2018 Northern Hemisphere heatwave at pre-industrial and higher global warming levels, Earth System Dynamics, 11, 855-873, 2020.

WMO: world meteorological organisation, https://public.wmo.int/fr/medias/communiqués-de-presse/état-du-climat-en-2021-des-phénom ènes-météorologiques-extrêmes-et-de, accessed: 2022-01-27, 2021.

880 Ye, K. and Messori, G.: Two leading modes of wintertime atmospheric circulation drive the recent warm Arctic-cold Eurasia temperature pattern, Journal of Climate, 33, 5565-5587, 2020.

Yiou, P., Jézéquel, A., Naveau, P., Otto, F. E. L., Vautard, R., and Vrac, M.: A statistical framework for conditional extreme event attribution, Advances in Statistical Climatology, Meteorology and Oceanography, 3, 17-31, https://doi.org/10.5194/ascmo-3-17-2017, 2017.

Yiou, S., Balembois, F., Schaffers, K., and Georges, P.: Efficient laser operation of an Yb : S-FAP crystal at $985 \mathrm{~nm}$, APPLIED OPTICS, 42 , 4883-4886, <GotoISI > ://000184940000014, 2003. 
https://doi.org/10.5194/wcd-2022-9

Preprint. Discussion started: 17 February 2022

(C) Author(s) 2022. CC BY 4.0 License.

(c) (1)
Weather and

Climate Dynamics

Discussions

Zappa, G., Shaffrey, L. C., Hodges, K. I., Sansom, P. G., , and Stephenson, D. B.: A Multimodel Assessment of Future Projections of North Atlantic and European Extratropical Cyclones in the CMIP5 Climate Models, Journal of Climate, p. 5846-5862, 2013.

Zscheischler, J., Martius, O., Westra, S., Bevacqua, E., Raymond, C., Horton, R. M., van den Hurk, B., AghaKouchak, A., Jézéquel, A., and Mahecha, M. D.: A typology of compound weather and climate events, Nature reviews earth \& environment, pp. 1-15, iSBN: 2662-138X Publisher: Nature Publishing Group, 2020. 